\title{
Mönchtum und Sarapiskult
}

Von

\author{
Lic. Dr. Erwin Preuschen
}

Eine Untersuchung der Entstehung und Entwicklung des christlichen Mönchtums bildet eine der verlockendsten Aufgaben für den Kirchenhistoriker. Denn wir haben es bei dem Mönchtum und seinem Verhalltnis zu der Kirche mit der paradoxen Thatsache zu thun, daß eine Bewegung, die sich grundsätzlich in den denkbar größten Gegensatz zu der Welt und ibren Ordnungen stellt, doch fort und fort in der stärksten Weise auf die Welt eingewirkt und daß sie ganz wesentlich die Kirche zu ihrer Wirksamkeit innerhalb der Welt befähigt hat. Die Entstehung dieser Erseheinung darzustellen, heißt die Entwicklung der Beziehungen zwischen dem Christentum und den in ihm wirksamen geistigen Kräften zur Welt schildern, wobei unter Welt die ganze Summe von Ordnungen vom Staat bis zur Familie und das gesamte Kulturleben mit Einschluß des Geisteslebens verstanden ist. Diese Entwicklung zu zeichnen, kann nicht Aufgabe der folgenden Erörterungen sein. Denn die verschiedenen Fäden aufzuzeigen, die sich durch die Geschichte der ersten Jahrhunderte hindurchschlingen, ist nicht die Sache einer Abhandlung. Hier soll vielmehr versucht werden, über einen Punkt Klarheit zu schaffen, der die Zusammenhänge des christlichen Mönchtums mit anderen Erscheinungen auf dem Gebiete der Religionsgeschichte betriftt.

Die Erforschung der Anfänge des Mönchtums hat in den letzten zwanzig Jahren eine lebhafte Förderung erfahren. Den Anlaß bot eine Untersuchung von $\mathrm{H}$. Weingarten, mit der die Zeitschrift für Kirchengeschichte 1876 ihren ersten Jahrgang eröffnete ${ }^{1}$ ). Die überraschenden Sätze, die Weingarten aufstellte und zu begründen suchte, zielten auf den Nachweis, daß das Mönchtum keineswegs in der konstantinischen Zeit entstanden, vielmehr erst nach dem Jahre 350 aufgekommen sei. Alle Berichte, die ein früheres Vorhandensein behaupteten, seien gefälscht, namentlich sei die Vita des Antonius, des «Vaters des Mönchtums», zu Unrecht dem Athanasius beigelegt worden. Alle späteren Quellen, Palladius in der historia Lausiaca, Rufin in der historia monachorum, Cassian in den Institutiones und collationes und vor allem Hieronymus in seinen Mönchsviten, seien als unglaubwürdig zu verwerfen, wenn sie von Mönchen berichteten, die bereits in konstantinischer Zeit gewirkt hätten. Vielmehr sei das Mönchtum in späterer Zeit als eine Fortsetzung des Mönchtums, wie wir es in den Sarapisheiligtümern finden, in Ägypten entstanden. Gegen die von verschiedenen

1) Der Ursprung des Mönchtums im nachkonstantinischen Zeitalter Zeitschr. f. KG. I. S. $1 \mathrm{fr}$. Eine etwas erweiterte Separatausgabe der Abhandlung erschien Gotha 1877. Nach ihr citiere ich. 
Seiten erhobenen Einwände suchte Weingarten seine Behauptungen sicher zu stellen und zugleich in mancher Hinsicht weiter auszubilden in dem Artikel "Mönchtum» in der zweiten Auflage von Herzogs Realencyklopädie für protestantische Theologie und Kirche 10, S. $758 \mathrm{ff}$. $\mathrm{Da} \beta$ er auch später an seinen Sätzen festhielt, zeigte er durch die Andeutungen, die er in der dritten Auflage seiner Zeittafeln der Kirchengeschichte (Rudolstadt 1888, S. 228) gab. Alle Behauptungen, die Weingarten aufgestellt und in anregender und lebhafter Darstellung verteidigt hatte, sind angegriffen und als übertrieben oder unbegründet zurückgewiesen worden. So seine Datierung der Anfänge des Mönchtums, seine Bestreitung der Echtheit der Vita Antonii des Athanasius, seine Behauptung von dem Zusammenhang der Ursprünge des Mönchtums mit bestimmten Kultformen der ägyptischen Religion ${ }^{1}$ ). Dennoch sind die Untersuchungen nicht wertlos gewesen. Es ist nicht bloß das negative Verdienst, daß sie wie ein belebender Luftzug gewirkt haben und daß durch sie zahlreiche Einzeluntersuchungen über die in Betracht kommenden Fragen veranlaßt worden sind, was ihnen einen bleibenden Wert in der Kirchengeschichte sichert. Höher ist das Verdienst anzuschlagen, daß sie eine religionsgeschichtliche Erscheinung aus ihrer Isolierung losgelöst und in einen größeren Zusammenhang hineingestellt haben. Mag auch der Weg, der dabei eingeschlagen wurde, verkehrt gewesen sein, so bleibt es doch immerhin ein dankenswertes Unternehmen, auf die notwendige Vergleichung mit Formen der religiösen Bethätigung hingewiesen zu haben, die anderen Kultformen entstammen.

Es ist daher erklärlich, wenn in neuester Zeit gerade diese Seite der Arbeit Weingartens mit besonderem Beifall begrüßt wird und zwar nicht sowohl von seiten der Kirchenhistoriker als derjenigen Philologen, die nach den tiefgreifenden Untersuchungen Useners in dessen Sinn die religionsgeschichtlichen Zusammenhänge aufzuhellen bemüht sind. Ein Beispiel dafür bietet der Vortrag, den A. Dieterich über Sarapis auf der letzten Versammlung deutscher Philologen und Schulmänner 1897 in Dresden gehalten hat und der, allerdings nur in einem sehr knappen Auszug, gedruckt vorliegt ${ }^{2}$ ). Hier ist das Mönchtum als eine späte Frucht des Sarapisdienstes aufgefaßt. Diese Vermutung würde eine schöne Bestätigung darin finden, wenn die Annahme neuerer Gelehrter im Rechte wäre, wonach der Organisator des mittelägyptischen Klosterwesens, Pachomius, vor seinem Übertritt zum Christentum Sarapismönch gewesen wäre ${ }^{3}$ ). Voraussetzung ist, daß es bei dem Sarapisdienst eine Institution gegeben hat, die irgendwie mit dem Mönchtum verwandt war. Auch solche Gelehrte, die der Behauptung, Pachomius sei zu einer Zeit seines Lebens ein Sarapismönch gewesen, widersprechen zu müssen geglaubt haben, sind doch bei dem Sarapismönchtum als einer realen Größe stehen geblieben ${ }^{4}$ ). Andere haben die fast zum Kanon gewordene Meinung, $\mathrm{da}$ es an den Sarapisheiligtümern Asketenvereine gegeben habe, zwar bekämpft, aber doch die Erscheinungen des religiösen Lebens, die zu jener Ansicht die Veranlassung gegeben haben, nicht befriedigend zu erklären vermocht. Es ist daher notwendig, zunächst die Grundvoraussetzung zu prüfen.

1) Es ist hier überflüssig, ein Verzeichnis der gesamten über die Frage angesammelten Litteratur zu geben. Was für die Untersuchung von Wichtigkeit ist, wird an seiner Stelle angefuhrt werden. - 2) Verhandlungen der XLIV. Versammlung deutscher Philologen und Schulmänner in Dresden, Leipzig 1897, S. 31-33. Eine Veröffentlichung des vollständigen Vortrages ist dort in Aussicht gestellt, bis jetzt aber noch nicht erfolgt. - 3) Revillout in der Revue Egyptologique I, 160 u. ö. Grützmacher, Pachomius u. d. alteste Klosterleben, Freiburg 1896, S. 39 f. Basset, Les Apocryphes éthiopiens VIII, Paris 1896, p. 5. Zöckler, Askese u. Mönchtum², Frankfurt a. M. 1897, S. 195. Batiffol, La litérature grecque, Paris 1897, p. 252. - 4) So z. B. Butler, The Lausiac history of Palladius (Texts and studies VI, 1), Cambridge 1898, p. $229 \mathrm{f}$. 
Im Anfang unseres Jahrhunderts gelangten durch Araber, die in Ägypten auf eigene Faust Ausgrabungen veranstaltet hatten, eine größere Anzahl von Papyrusfetzen in die europäischen Museen, die leider nicht zusammen blieben, sondern nach verschiedenen Orten zerstreut wurden. Den Hauptanteil erhielt Paris, andere kamen nach Leyden, London, Turin, Rom, Berlin und Wien. Im ganzen waren es über 150 Nummern. Mehr als die Hälfte von ihnen stammte aus dem Ruinenfelde von Saqqârah, der Stätte des alten Memphis ${ }^{1}$ ). Ob sie ursprünglich z. T. einem Archiv oder einer Registratur angehört haben, wie man früher annahm, ist nicht sicher. Neben Dokumenten, die den Präsentationsvermerk eines Beamten tragen, finden sich auch Entwürfe zu Eingaben in verschiedener Gestalt, die niemals an die amtliche Stelle gelangt sein können. Deshalb hat die Vermutung manches für sich, daß sie großenteils wohl aus alten Kehrichthaufen herausgelesen sind, auf die man alle möglichen Ábfälle, auch litterarische der niedersten Gattung, wie Rechnungen, Kontrakte u. a., warf. Das Grab im Wüstensande, der schon zur Zeit Strabos Memphis und besonders das große Sarapeum von Memphis bedeckte ${ }^{2}$ ), hat diese Denkmäler vergangener Tage uns im wesentlichen unversehrt erhalten. Die Urkunden sind sämtlich veröffentlicht ${ }^{3}$ ), ohne daß freilich, was leicht verständlich ist, die Form dieser Veröffentlichungen den Anforderungen entspricht, die man heute zu stellen berechtigt ist. Aus ihnen ergiebt sich ein anschauliches, wenn auch nicht immer ganz klares Bild von dem öffentlichen und privaten Leben in Memphis zur Zeit der älteren Ptolemäer. Eine größere Anzahl beschäftigt sich mit den Angelegenheiten des Kultuspersonales in dem großen Sarapeum von Memphis. Diese Stücke sind es, die hier in Betracht kommen.

Eine häufig vorkommende Persönlichkeit ist ein gewisser Ptolemäus, der Sohn des Glaucias, der Nachkomme eines Macedoniers, der in dem Lande zurückgeblieben war, als die griechischen Söldnerscharen Ägypten eroberten. Er lebte in dem "großen Sarapeum» und zwar, wie er stets betont, als xórcoyoఢ . Was mit diesem Ausdruck gemeint ist, muß zunächst noch offen bleiben. Ein Schluß auf die Bedeutung, in der das Wort hier gebraucht ist, wird erst möglich sein, wenn man aus den verschiedenen Angaben, die er über sich selbst und seine Beschäftigung im Tempel macht, ein Bild von seiner Stellung zu gewinnen sucht. Neben ihm treten uns zwei Priesterinnen entgegen, die ebenfalls in dem Sarapeum beschäftigt waren und als deren Beschützer sich Ptolemäus zeigt. Ihre Namen sind Thaes (nach der wechselnden Orthographie - eigentlich Unorthographie - der Urkunden wird der Name

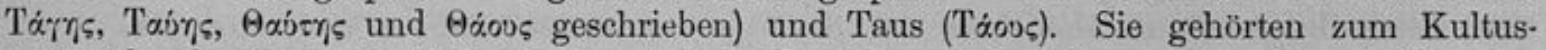
personale, da sie gelegentlich als ihre Aufgabe bezeichnen, der Isis und dem Sarapis Spenden darzubringen. Über ihre Geschicke erfahren wir aus einer Petition, die sie an den König Ptolemäus und die Königin Kleopatra richteten, die allerdings vielleicht niemals an ihre

1) Uber den heutigen Zustand vgl. Baedeker, Unter-Ägypten, S. $409 \mathrm{ff}$. - 2) Strabo, XVII, 1, 32 ,

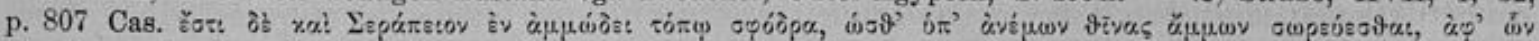

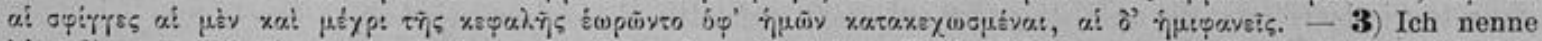
hier diese Publikationen, nach denen im folgenden citiert ist. Paris: W. Brunet de Presle, Notices et textes des papyrus grecques du musée du Louvre et de la bibliothèque impériale. In den Notices et extraits des Mss. de la bibliothèque impériale XVIII, 2 (Paris 1865) mit Photolithographien der Texte, die meist die Kontrolle ermöglichen ( $\mathrm{Nr} 22-51)$. Leyden: Papyri Graeci Musei antiquarii publici Lugduno-Batav. ed. C. Leemans I (Lugd.-Batav. 1843), II (ib. 1884). In Betracht kommen BCDE. London: [J. Forshall], Deseription of the Greek Papyri in the British-Museum I (London 1839); Nr. II-XVIII. J. Kenyon, Greek Papyri in the British-Museum I, Lond. 1893. [Nach Kenyon ist citiert; die Nummern in Klammern sind die aus Forshalls Description.] Turin: A. Peyron, Papyri Graeci Regii Taurinensis Musei Aegyptii (Taurin. 1826/27). Rom: A. Mai, Classici auctores V (Rom 1833), p. $352 \mathrm{sqq.} 601 \mathrm{sqq.}$. Die zahlreichen neueren Publikationen, die sonst außerordentlich wichtige Aufschlüsse über die Geschichte Ägyptens, seine Verwaltung, Verfassung und Religion von der Ptolemalerzeit bis zur Herrschaft der Araber gebracht haben, enthalten nichts, was beitragen könnte, die hier erörterte Frage weiter zu klaren. 
Adresse gelangt ist ${ }^{1}$ ). Sie lautet: «Dem Könige Ptolemäus und der Königin Kleopatra, seiner Schwester, den Philometores, den Göttern, Gruß. Thaues und Taus, die als Priesterinnen in dem großen Sarapeum bei Memphis fungieren, indem sie dem Sarapis Spenden darbringen für Euch und Eure Kinder, und die in mehrfacher Hinsicht Unrecht erfahren von Nephoris und Pachrates [ihrem Sohne] ${ }^{2}$ ), nehmen zu Euch unsere Zuflucht, damit wir unser Recht erlangen. Die genannte Nephoris verließ unsern Vater und wohnte mit einem gewissen Philippus zusammen [zwischen der Zeile: verband sich mit einem Bürger von Memphis, Philippus] und obgleich sie das gethan hatte, nahm sie doch nicht die Miene einer Sünderin an, sondern half noch dazu mit, daß Philippus ihn (d. h. den Vater) in den gegenwärtigen wirren Zeitläuften beiseite schaffte. Dieser (Philippus) lauerte an der Thüre seines Hauses, das auf dem ägyptischen Markt am Flusse liegt, als. unser Vater herausging und als er es (d. h. das Auflauern) wahrnahm und in den Fluß schwamm und sich nur mit Mühe auf eine Insel rettete und von einem vorüberfahrenden Schiff aufgenommen wurde, und, da er es nicht mehr wagte zurückzukehren ${ }^{3}$ ), sich nach Herakleopolis begab, wo er, weil wir nicht mehr bei ihm waren, vor Gram starb. Seine Brüder aber fuhren hinauf und brachten ihn nach der Nekropole von Memphis; bis jetzt aber hat ihn Nephoris noch nicht zu begraben gewagt. Sein Vermögen, das vom Fiskus eingezogen war, hat Nephoris eingelöst, indem sie die Hälfte des uns und ihr gemeinschaftlich gehörigen Hauses hergab um 60 Kupfertalente und sie behielt einen Vermögensteil von 60 Kupfertalenten zurück und an Miete nimmt sie monatlich 400 Kupfertalente ein [und davon giebt sie uns nichts ab]. Nicht zufrieden damit trieb sie uns auch noch aus dem Hause, so daß wir in Gefahr waren, zu verhungern. Wir aber erinnerten uns an einen gewissen Ptolemäus, der zu denen gehört, die in dem großen Sarapeum sich in der жaroy $\dot{\eta}$ befinden, einen Freund unseres Vaters. Zu diesem gingen wir und fanden unsern Unterhalt. Als nun die Trauerfeier für den Apis stattfand, führte man uns hinab, um die Klage abzuhalten. Die Freunde unserer Mutter überredeten uns, daß wir ihren Sohn zu uns nahmen, damit er uns diene. Als das geschehen war, blieb er eine Zeit lang bei uns, nahm dann [das von der Verwaltungsbehörde] ausgestellte [Schriftstück], betreffend das Quart Öl und die Leinwand, die uns geliefert werden mußte [z. d. Z. „das Eine, das uns von Euch geliefert werden mußte"] und nahm uns diese Urkunde heimlich weg, stahl uns auch das Geld, das wir gerade hatten [und andere Dinge], und begab sich wieder zu seiner Mutter, so daß wir nicht einmal das Notwendigste haben. Wir bitten Euch also, dieses Bittgesuch an Dionysius, den Strategen zu senden, daß er dem Mennides [Apollonius], dem Verwalter, und Dorion, dem Sekretär, schreibt, daß sie weder das uns zukommende Öl noch das Kiki-Öl noch sonst etwas von unserem Besitze behält, und daß sie uns das väterliche Erbe, das sie widerrechtlich behält, herausgiebt, damit wir durch Euch Hülfe erfahren. Lebt wohl!s

Die Bittstellerinnen verraten sich in dem Schreiben als wenig gebildete Leute. Die Konstruktionen sind durch das ausgezeichnet, was noch heute für die Schreibweise von Leuten charakteristisch ist, die nicht gewohnt sind, mit der Feder umzugehen: durch die endlose Aneinanderreihung der Sätze mit «und . Was sich aus dem Schreiben über die Stellung der beiden Bittstellerinnen im Sarapeum entnehmen läßt, ist nicht viel. Die Not hat sie dorthin getrieben, nicht ein Gelübde. Ihre Aufnahme verdanken sie Ptolemäus, dem жd́.roð०६,

1) Par. 22. Vgl. den Entwurf dazu Par. 23. Vgl. auch 26. Leyd. B, u. a. Brunet de Presle setzt die Petition mit gutem Grund in die Jahre 163 oder 162. S. Notices, p. 274. - 2) Die eingeklammerten Worte stehen in der Urkunde zwischen den Zeilen. Sie stellen offenbar Korrekturen vor, die man vor der Ein. reichung anzubringen für notwendig hielt. - 3) Die Scene ist nach dieser Schilderung nicht ganz deutlich. Nach 23, $5 \mathrm{ff}$, drang Philippus mit gezlicktem Schwerte auf den Vater ein, um ihn umzubringen. Da das Haus unmittelbar am Flusse lag, rettete sich der Angegriffene, indem er in das Wasser sprang und im Schwimmen sein Heil suchte. 
der als Freund ihres Vaters für sie zu sorgen sich verpflichtet fühlte. Daraus, daß die beiden Mädchen uns in priesterlichen Funktionen entgegentreten, ergiebt sich, daß sie durch Ptolemäus eine bestimmte Anstellung unter dem Kultuspersonale des Sarapeums gefunden haben. Das ist aber nur denkbar, wenn Ptolemäus selbst in irgend einer Weise zu dem Tempelpersonale gehörte. Eine besondere Bezeichnung seines Amtes kann daher, da nichts anderes

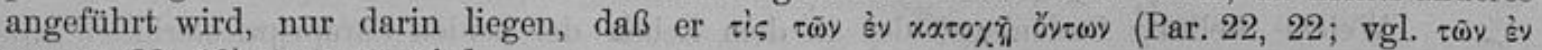
\%.นซก๊ 23, 18) genannt wird.

Die Funktionen, die jene beiden Mädchen ausübteu, werden genauer angegeben.

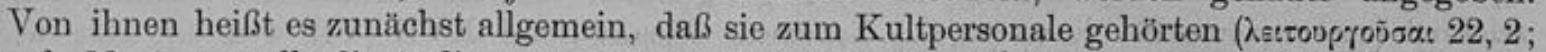
vgl. 23, 1, wo allerdings die erste Zeile und mit ihr die in Frage kommenden Worte z. T.

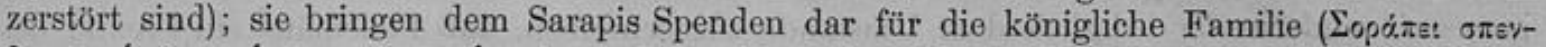

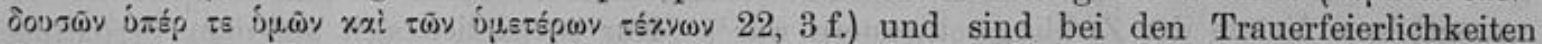

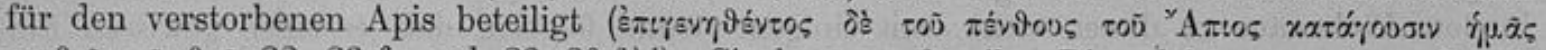

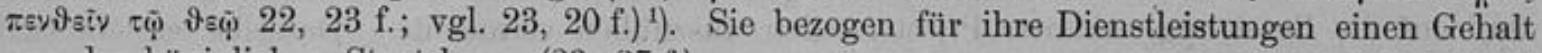
aus der königlichen Staatskasse $(23,27 \mathrm{f}$.).

Diese Resultate einer Erwägung der in dem oben deutsch mitgeteilten Schriftstück enthaltenen Angaben lassen sich durch andere Urkunden noch ergänzen. Aus dem Londoner

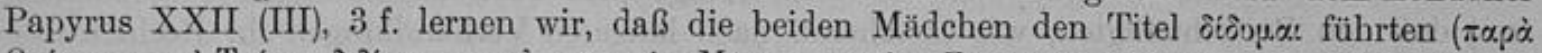

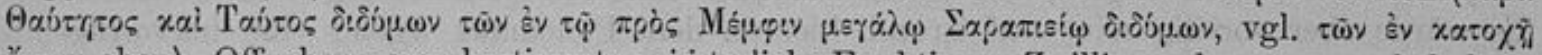

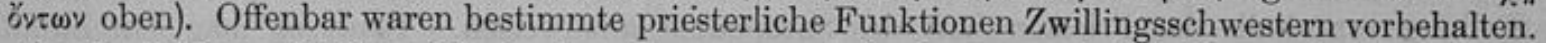
Als die beiden mittellos sich in dem Sarapeum einfanden, verschaffte ihnen Ptolemäus die Stelle. Von ihren Vorgängerinnen ist auch gelegentlich die Rede. Sie berufen sich auf die Naturallieferungen an Öl und Kiki, die diese erhalten hatten und auf die daher auch sie

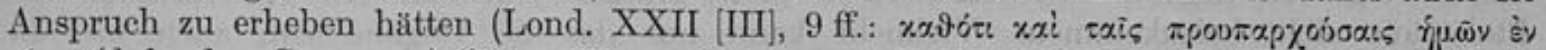

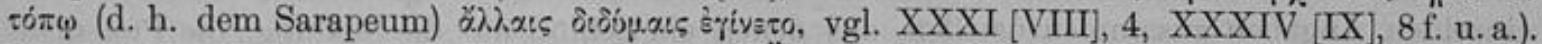

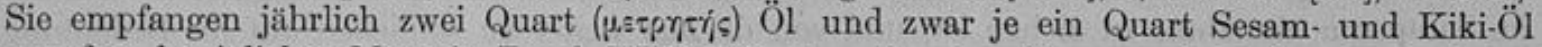

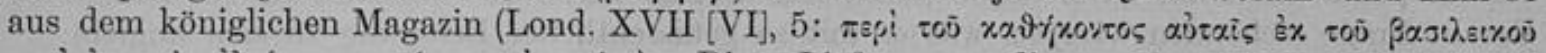

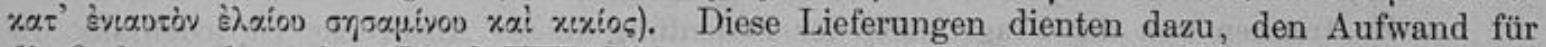

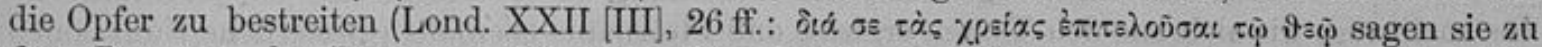
dem Beamten, der ihnen zur Erlangung ihres Rechtes behülflich sein soll; vgl. Par. 26, $47 \mathrm{ff}$; 29, 22 ff. u. a.). Daß sie in dem Asklepieion, d. h. dem dem Sarapis-Asklepios geweihten Tempel in dem großen Tempelkomplex des Sarapeums angestellt waren, ist aus dem Londoner

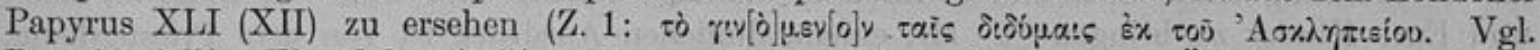
Par. 26, $6 \mathrm{ff}$.). Ebendaher ( $1 \mathrm{ff}$.) erfahren wir, daß sie außer auf die Öllieferungen auf drei Brote täglich Anspruch hatten, die, wie das Folgende lehrt, ebenfalls bei dem Opfer gebraucht wurden ${ }^{2}$ ). Denn als den beiden Priesterinnen die Brotlieferungen dureh die Eifersucht anderer Priester entzogen wurden, mußten sie die Opfer einstellen. Diese letztere Lieferung muß irgendwie mit den Trauerfeierlichkeiten bei dem Tod des Apis zusammenhängen. Denn

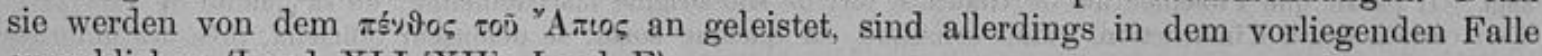
ausgeblieben (Lond. XLI [XII]; Leyd. E).

1) Bei dem Tode des Apisstieres fanden in Ägypten öflentliche Trauerfeierlichkeiten statt. Ebenso in jedem Jahr ein Trauerfest. Hier handelt es sich um dieses offizielle Trauerfest, das in Memphis, der

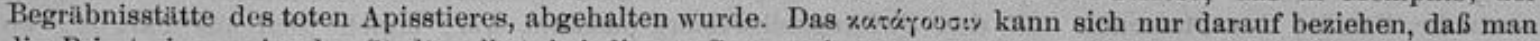
die Priesterinnen in der Stadt selbst bei diesen Ceremonien verwandte. Denn das Sarapeum lag höher als die Stadt (Strabo XVII, 1, 32). Über die Landestrauer beim Tode des A pis hat Jablonski, Pantheon Aegyptiorum II (Francof, ad Viadr.), p. 204 sq. einige Stellen aus den alten Schriftstellern gesammelt. Vgl. Pietsehmann bei Pauly-Wissowa, Real-Encyklop. d. klass. Altertumswissensch. I, 1, 2808, $40 \mathrm{ff}$. Plutarch, De Iside et Os. 35. - V) Vgl. zu diesen Opfern Brunet de Presle, Mémoire sur le Sérapeum in den Mémoires présentés par divers savants à l'Académie des inscriptions et de belles lettres de l'Institut National de France, Io série, $t$. II (Par. 1852), p. 562 s. Eine Berechnung über die in einem Jahre zu leistenden Lieferungen findet sich in Pap. Lond. XVIII (XIV). 
In diesen Dokumenten spiegelt sich ein gutes Stück der Leiden der Priesterschaft wieder. Für die Leistungen, die man von ihnen verlangte, hatten sie Anspruch auf Entschädigung seitens der königlichen Kasse, aus der die Bedürfnisse für den Kult bestritten wurden. Blieben die Leistungen aus, so stockte auch der Opferdienst und das Tempelpersonal war der Not preisgegeben.

Welche Stellung Ptolemäus, der in dem Leben der beiden Sarapispriesterinnen eine so bedeutungsvolle Rolle spielt, in dem Opferbetrieb einnahm, ist aus dem im vorhergehenden Erörterten noch nicht ersichtlich. Er wird gelegentlich als der Anwalt der Zwillinge be-

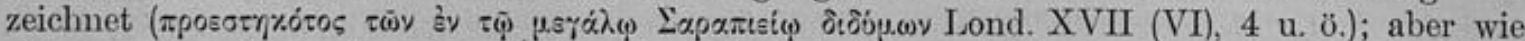
sich aus der oben mitgeteilten Urkunde ergiebt, ist das nicht ein Ausfluß seiner Stellung gewesen, sondern war lediglich dem Umstande zuzuschreiben, daß Ptolemäus ein Freund des verstorbenen Vaters der Z willingsschwestern war $\left.^{1}\right)$. Nur soviel ließ sich aus dem Verhältnis, in dem Ptolemäus zu diesen steht, mit einigem Grund folgern, daß er einen gewissen Einfluß auf die Besetzung vakanter Priesterstellen auszuüben vermochte. Dasselbe ergiebt sich auch aus dem weiteren Umstande, daß die von ihm eingereichten Bittgesuche für die beiden Priesterinnen zu einem lebhaften Schriftenaustausch der in Betracht kommenden Instanzen führten und zwar auf Grund einer von dem Könige persönlich angeordneten Untersuchung und daß den Benachteiligten, wie es scheint, nach längeren Verhandlungen ihr Recht wurde. Es würde aber voreilig sein, auf Grund hiervon dem Ptolemåus irgend eine hervorragende Stellung innerhalb der Priesterschaft des Sarapeums anzuweisen. Denn es mag ein Zufall sein, daß gerade diese Korrespondenz uns in solchem Umfange erhalten ist, während vielleicht zahllose ähnliche, die einen ähnlichen Erfolg hatten, verloren gingen oder noch im Sande vergraben liegen. Mit Schlüssen a priori ist also jedenfalls der Persönlichkeit des Ptolemäus nicht beizukommen. Vielmehr kann nur das die Aufgabe sein, auch hier die einzelnen Angaben zusammenzustellen, aus denen ein Schluß auf die Stellung, die Ptolemäus im Sarapeum einnahm, zu ziehen ist, und von da aus weiter zu schließen auf die Bedeutung

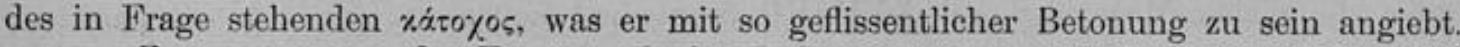

$\mathrm{Zu}$ trennen von der Frage nach der Bedeutung dieses Ausdrucks ist jedenfalls die Beobachtung, die sich aus den Texten ergiebt, daß Ptolemäus ebenfalls priesterliche Funktionen ausgeübt hat. In einem Bittgesuch, das die Aufnahme seines Bruders in eine in Memphis stehende Truppenabteilung zu bewirken sucht, wird als Grund angegeben, daß der Bittsteller an der Löhnung teilnehmen und dadurch in die Lage versetzt sein will, «die Opfer für Euch und Eure Kinder zu bringen " \%). Mit einem ähnlichen Ausdruck ist von dem Priesterdienst der Zwillinge die Rede (s. o. S. 7). Daß man mit dieser Eigenschaft als Priester nicht die andere als жáro\%os identifizieren darf, ergiebt sich daraus, daß von andern Persönlichkeiten

1) Brunet de Presle hat also schwerlich mit seiner Bemerkung recht, wenn er Notices, p. 271 sagt: «Il paraît que Ptolémée fils de Glancias, fort de son origine macédonienne, de sa qualité de xúro\%os et d'un certain degré d'instruction, s'était constitué, en quelque sorte, le défenseur officieux, près des autorités grecques, de toutes les personnes qui, dans le Sérapéum, avaient à se plaindre de quelque injustices. Daß er auch in dem in Par. 24 behandelten Falle als Anwalt auftrat, ist kein Beweis dafü. Denn dieser Papyrus ist so verstümmelt erhalten, daß man kein deutliches Bild von der hier vorliegenden Sachlage erhalten kann. Möglicherweise waren es auch hier persönliche Gründe, die ihn zum Einschreiten veranlaßten. - Wie nahe auch die Familie des Ptolemäus mit den Zwillingsschwestern bekannt war, ergiebt sich aus Par. 32, wo Lysimachus, ein Bruder des Ptolemilus, in einer Briefüberschrift neben diesem und seinem andern Bruder

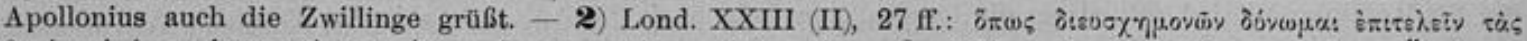

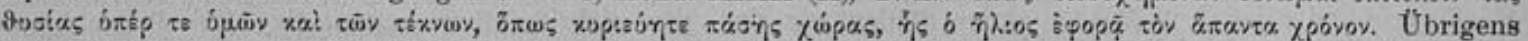
ist bemẹrkenswert, daß Ptolemäus den Ausdruck $\imath_{\imath} p \alpha \pi \varepsilon \dot{\varepsilon} \varepsilon v$, der speciell die priesterlichen Funktionen bezeichnet (vgl. Letronne, Recueil des inser. greeques et latines de l'Egypte I [Paris 1842], p. 304 s.), nie von sich anwendet.

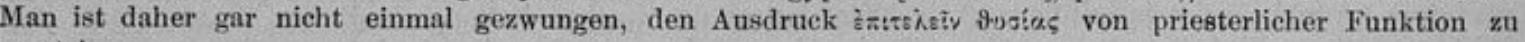
verstehen. 
die Rede ist, die nicht Priester und doch xd́roxot waren ${ }^{1}$ ). Bei Ptolemäus und bei den Zwillingen Thaes und Taus - denn auch diese scheinen Par. 50, 14 als жóroyo bezeichnet zu werden - liegt die Sache also nicht so einfach. Sie waren Priester und Priesterinnen in dem egroßen Sarapeum bei Memphis"; dazu befanden sie sich auch in der xaroxí.

Es empfiehlt sich daher von den Fällen auszugehen, in denen uns die кагохri bezeugt ist, ohne daß die betreffenden Personen dem Priesterstande angehörten. Dadurch wird eine sonst leicht mögliche Konfusion am ersten vermieden und zugleich ein deutlicherer Begriff vom Wesen dieser Institution ermöglicht werden. In zwei Urkunden, von denen sich

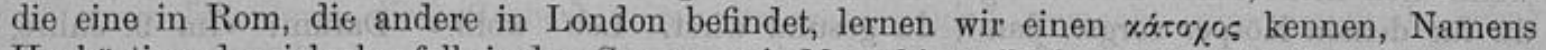
Hephästion, der sich ebenfalls in dem Sarapeum in Memphis aufhielt. Die Umstände, unter denen er in das Sarapeum kam, lassen sich aus den beiden Briefen noch mit einiger Deutlichkeit erkennen. Der erste Brief lautet $\left.{ }^{2}\right)$ :

๔Dionysius grüßt seinen Bruder Hephästion.

Wenn du gesund bist und alles andere dir nach Wunsch geht, so wäre ${ }^{3}$ ) das alles, was ich wünsche. Ich selbst bin auch gesund und vergnügt, auch die Kinder und Isias ${ }^{4}$ ) und dein Kind und alle im Hause. Ieh habe deinen Brief erhalten, in dem du mitteilst, daß du aus großen Gefahren errettet seist und daß du dich in $x .20 \times \gamma \eta$ befindest, und danke ${ }^{5}$ ) den Göttern dafür, daß du gesund bist. Ieh wünsche aber, daß du wieder in die Stadt kommst, wie auch Konon und die übrigen ....6) Und Isias hat dein Kind, als es mit ihm zum äußersten gekommen war, mit allen Mitteln durchgebracht. Nachdem sie jetzt solche Zeiten durchgemacht hat, [hofft sie], dich jetzt zu sehen und etwas aufatmen zu können. Denn du darfst durchaus nicht, nachdem du [eben $\left.\left.{ }^{7}\right)\right]$ hinaufgegangen bist, dort bleiben, bis du etwas verdient hast und mitbringen kannst. Vielmehr sucht jeder, wenn er Gefahren entgangen ist, schnell nach Hause zu kommen, um seine Frau, Kinder und Freunde zu begrüßen. Du wirst also gut thun, wenn dich nichts hindert, kurzer Hand zu versuchen, herzukommen und für deinen Körper sorgen, damit du ganz gesund wirst. Leb' wohl.» Datum: «Im ersten (9. ?) Jahre $\left.{ }^{8}\right)$, am 1. Epiphi». Die Rückseite trägt die Adresse: ‘An Hephästion ».

Das zweite, offenbar bald darauf abgesandte Schreiben, das vielfach auch im Wortlaute mit diesem übereinstimmt, lautet $\left.{ }^{9}\right)$ :

"Isias [grüßt] Hephästion, ihren Gemahl.

Wenn du gesund bist und es dir im übrigen nach Wunsch geht, so ist das alles, was ich beständig von den Göttern erbitte. Ich selbst bin gesund, auch das Kind und alle im Hause denken fortwährend an dich. Deinen Brief habe ich von Horus erhalten, in dem du

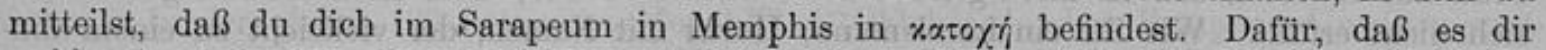
wohl geht, habe ich gleich den Göttern gedankt. Damit aber, daß du nicht kommst, nachdem sich alle Verheißungen dort erfüllt haben (?), bin ich nicht zufrieden, weil ich mich und das Kind aus diesen Zeiten durchgesteuert habe und wegen des Getreidepreises in die

1 Man hat das übersehen, wenn man annahm, daß die xároyo: als solche priesterliche Funktionen ausgeủbt hätten. Reuvens, Lettres à Mr. Letronne sur les papyrus bilingues et grecs (Leyde 1830), p. 85. Leemans, Papyri graeci Mus. gr. antiq. publ. Lugd.-Batav. I (1843), p. 7 sq. Lucius, D. Therapeuten u. ihre Stellung in d. Geschichte d. Askese (Straßburg 1879), S. 201. - 2) S. A. Mai, Classici auctores V (Rom. 1833), p. 601 sq. 3) Mai hat sìt; ; Lond. XLII (XVIII), 3 (Kenyon p. 30) sinc; letzteres ist richtig, vgl. Par. 44, 2 u. a. - 4) Isias

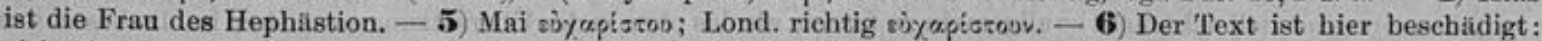

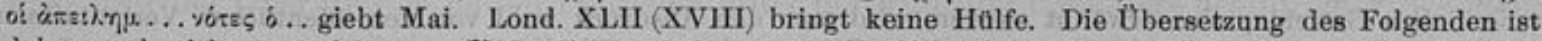
daher auch nicht ganz sicher. - - ) Im Text orsvās, was keinen Sinn giebt; denn offenbar ist Hephästion schon geraume Zeit von Hause weg. Die Lesungen Mais sind nicht ohne Fehler (vgl. Brunet de Presle, Notices p. 295, n. 2); möglicherweise hat er sich auch hier verlesen. Lond. XLII (XVIII) hilft auch hier nicht weiter. -8) Statt La liest Lond. XLII (XVIII) Lง. - 9) Pap. Lond. XLII (XVIII) Forshall, Description, p. $46 \mathrm{ff}$. Kenyon, Catalogue of the Greek Papyri in the Br. Mus. 1, 30. Besserer Text bei Deißmann, Bibelstudien, Marburg 1895, S. 209 f., bei dem die Lesungen von Wilcken, Gött. Gelehrte Anzeigen 1894, S. 722, verwertet sind. 
schlimmste Lage gekommen bin und geglaubt habe, ich würde durch deine Rückkehr etwas aufatmen können. Du aber denkst nicht daran, zurückzukehren und siehst nicht auf unsere Lage, obschon wir bereits bei deiner Anwesenheit an allem Mangel litten, geschweige denn, nachdem schon so lange Zeit vergangen ist und wir solche Zeiten haben durchmachen müssen und du doch noch nichts geschickt hast. Und doch berichtet Horus, der den Brief gebracht

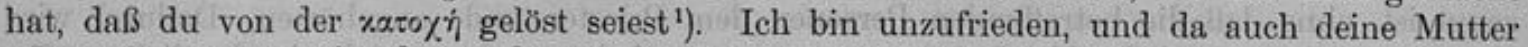
schwer daran trägt, wirst du gut daran thun, ihret- und unseretwegen in die Stadt zurückzukehren, wenn dich nicht etwas Notwendiges zurückhält. Du wirst uns einen Gefallen erweisen, wenn du für deinen Körper sorgst, damit du gesund wirst. Leb' wohl,s Datum: *Im 9. Jahre, am 30. Epiphi». Adresse: "An Hephästion».

$\mathrm{Da}$ die beiden Briefe enge zusammengehören, zeigt ein Blick auf den Inhalt. Nicht nur Eingang und Schluß sind fast gleichlautend, sondern auch im einzelnen stimmen viele Ausdrücke wörtlich überein; und die Situation ist von beiden so gleichmäßig geschildert, daß ein Zweifel nicht möglich ist. Eine Frau schildert ergreifend ihre Lage; ihr Mann ist einer großen Gefahr entgangen; sie ist nun mit ihrem Kinde allein zurückgeblieben, und da der Ernährer fehlt, in große Not gekommen. Zwar hat sie sich durch die schlimmen Zeiten ${ }^{2}$ ) mühsam durchgeschlagen, aber nun fleht sie, daß ihr Mann wieder zurückkommen möge, damit die Not ein Ende nimmt, und ihr Schwager unterstützt eindringlich diese Bitte um Rückkehr.

Welcher Art die Gefahren gewesen sind, aus denen Hephästion gerettet wurde, wird nicht genauer angegeben. Aber eine Vermutung darüber ist uns, wenn man den Wortlaut genau prüft, doch an die Hand gegeben. Beide Briefe beginnen mit dem Ausdruck der Freude darüber, daß es dem Adressaten gut geht. Beide schließen mit dem Wunsche, daß er für seinen Körper Sorge tragen möge, damit er gesund werde $\left.{ }^{3}\right)$. Die Todesgefahr, in der Hephästion geschwebt hatte, wird also wohl eine schwere Krankheit gewesen sein. Beachtet man aber in dem ersten Brief die Zusammenstellung von "Errettung aus großen Gefahren»

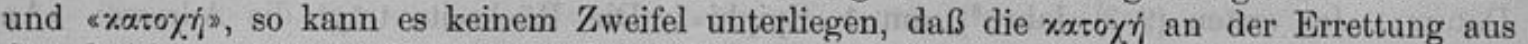
den Gefahren und der Erlangung der Gesundheit, wofür den Göttern Dankopfer gebracht werden, beteiligt ist. Zu welcher Auffassung vom Wesen dieser Institution unser Sehluß führt, kann hier zunächst noch nicht erörtert werden.

Abgesehen von dieser wichtigen Folgertung ergeben sich aber auch noch andere wichtige Momente für die Bestimmung des Begriffes. Aus dem Briefe der Isias sehen wir, daß es möglich gewesen sein muß, irgendwie sich in dieser Lage Geld zu verdienen. Hephästions Frau hat erwartet, daß er ihr irgend etwas schicken würde; aber ihre Hoffnungen haben sich nicht erfüllt. Wie ihr ein Landsmann, Horus mit Namen, der vielleicht zu einem ähnlichen Zwecke das Sarapeum aufgesucht hat, bei seiner Rückkehr berichtete, hat ihr Mann

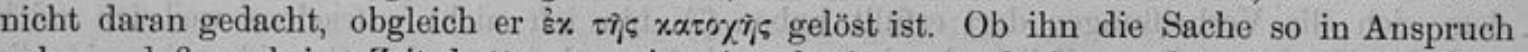
nahm, daß er keine Zeit hatte, an seine Angehörigen zu denken, oder ob es mit seiner Gemütsverfassung zusammenhing, läßt sich nicht sagen. Jedenfalls erwartete man etwas derartiges von ilhm, hat also eine vom Sarapeum aus erfolgende Fürsorge für die Seinen doch für möglich gehalten.

1 Der Ausdruck findet sich auch Par. 51,26 und bezeichnet die offizielle Beendigung der $* a \tau \sigma \%$. - 2) Die xaspot zo:oivo: sind vielleicht nicht so allgemein zu fassen, als das oben in der Übersetzung geschehen ist. Da besonders die hohen Getreidepreise erwähnt werden, wird man den Ausdruck wohl von den offentlichen Verhaltnissen verstehen mulssen. Wir wissen, daß in diese Zeiten politische Wirren fallen, die auch für beguterte Leute unangenehme Folgen hatten. - 3) Übrigens gehören diese Formeln zu der Sitte in den Briefen. Die Briefeinginge sind nach derselben stereotypen Formel gebildet, die wir auch noch in Nr. 7 beobachten können (vgl. Deißmann, Bibelstudien, Marburg 1895, S. 189 ff.). Ebenso enthät der Schluß häufig die Mahnung, für seine Gesundheit bedacht zu sein. Da aber diese Briefe größtenteils an dieselben Personen gerichtet sind

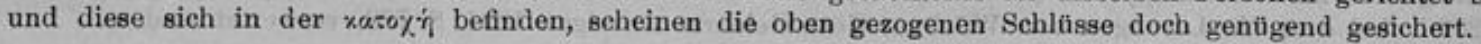


Ferner ergiebt sich mit voller Sicherheit aus den Briefen, daß die Beendigung des mit

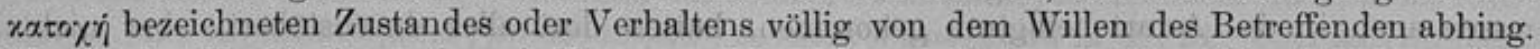
Man fordert Hephästion auf, nach Hause zurückzukehren, mit der alleinigen Einschränkung š̆ $\pi$ ep

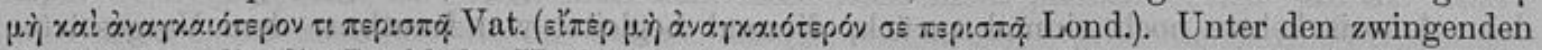
Umständen, die die Rückkehr Hephästions verzögern könnten, darf wohl ein direkter Wink der Gottheit verstanden werden. Liegt ein solcher göttliche Wink nicht vor, so hat er keinen Anlaß, mit der Rückkehr zu warten. Denn wie ihm sein Bruder schreibt, versucht jeder, wenn er aus den Gefahren befreit ist, so schnell als möglich wieder nach Hause zu kommen.

Schon durch diese Beobachtungen ist es unmöglich gemacht, die $x \propto \tau \sigma \gamma \dot{\eta}$ als etwas dem Priestertum Analoges aufıufassen. Wäre das der Fall, so könnte der, der einmal in den Verband der Kultusbeamten eingetreten ist, wohl nicht so ohne weiteres aus diesem Verbande ausscheiden, wann es ihm gut schiene. Aber es wäre auch ein in der Geschichte der Religionen völlig unerhörter Gedanke, wenn jemand, um seine Gesundheit zu erlangen, einen Priesterdienst übernähme. Vielmehr müssen die, die zu Priestern einer Gottheit erwählt werden, im Gegenteil untadelig sein.

Hiermit ist eine einigermaßen sichere Basis gegeben, von der aus es gelingen kann,

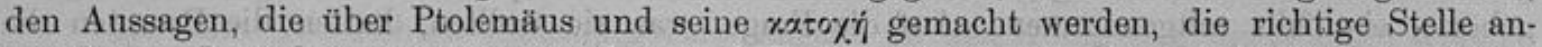
zuweisen. Bemerkenswert ist zụnächst, daß Ptolemäus überall ohne Ausnahme in seinen Bittgesuchen seinem Namen den Umstand hinzufügt, daß er sich in жaroy $\dot{\eta}$ befindet und zwar sehr häufig mit der genaueren Bestimmung der Dauer durch Angabe des Jahres. Das kann nur dann einen Sinn haben, wenn einmal eine längere Dauer nicht zu den gewöhnlichen Erscheinungen gehörte und sodann, wenn diese Thatsache der betreffenden Persönlichkeit irgend-

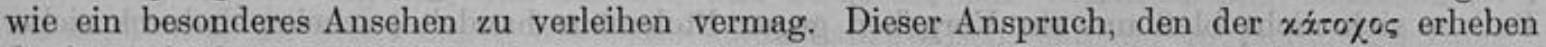
durfte, läßt darauf schließen, daß man ihm eine besondere Stellung der Gottheit gegenüber anwies, die wohl über das $\mathrm{Ma}$ von Autorität, das der Priester als solcher genoß, noch hinausging.

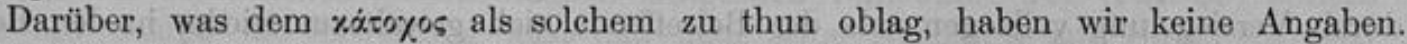
Wie oben (S. 8 f.) gezeigt wurde, hat die Aussage, daß Ptolemäus opferte, nichts mit der Thatsache zu thun, daß er ein ※d́ro\%ం૬ war. Diése Angaben, die in den Berichten zudem völlig in den Hintergrund treten, dürfen also hier nicht verwertet werden. Dahin gehören wohl die Angaben über die Wohnung des Ptolemäus. Nach Par. 37, 4 (vgl. 41, 18. 35, 4) verweilt

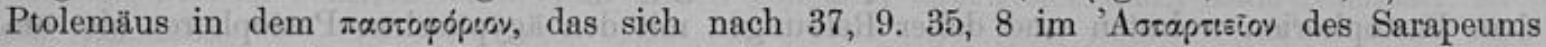

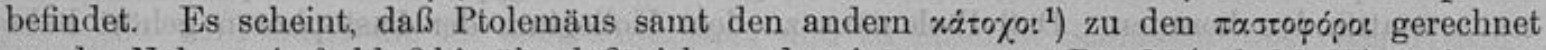
wurde. Näherer Aufschluß hierüber läßt sich aus dem interessanten Par. 35 (vgl. 36, 37) gewinnen.

In dem Jahre 163 hatten im Monat Thot (Oktober) in dem Sarapeum Unruhen stattgefunden, über deren Anlaß wir nichts Näheres erfahren. Solche Unruhen waren, wie uns die Urkunden lehren, nichts Seltenes in den heiligen Hallen, wo man angeblich die Rache nicht kannte. Und aus den Beschwerden, die von seiten der Griechen gegen die Ägypter erhoben wurden, läßt sich noch schließen, daß der Streit der Nationalitäten auch das Tempelgebiet berührte ${ }^{2}$ ). Bei dem 163 ausgebrochenen Aufruhr war nun auch Ptolemäus in Mitleidenschaft gezogen worden. Es scheint, daß die Sache in dem Anubisheiligtum, das neben dem eigentlichen इxpassiov und dem 'A bezirkes bildete, zuerst angegangen war. Denn der in dem Anubisheiligtum stationierte Polizeichef und der Oberpriester hatten Polizisten unter der Führung besonders beauftragter Beamten,

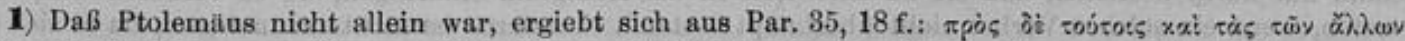

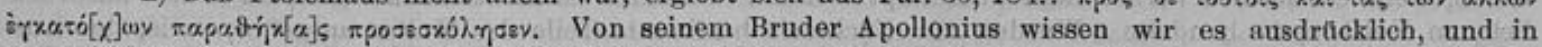
Lond. XXIV (XV) lernen wir noch einen andern xároxo૬, Namens "A pu,a:ৎ, kennen. - 2) Vgl. Par. 36, $11 \mathrm{ff}$. Man dringt mit Gewalt in das Heiligtum und will Ptolemäus herausholen, wie es schon fruher bei Aufstilnden versucht worden ist, weil er ein Grieche war. 
des Ptolemäus und Amosis, ausgesandt, um nach den versteckten Waffen zu suchen. Sie waren auch in das Astarteheiligtum gekommen, hatten dort alles durchstöbert, aber nichts Verdächtiges gefunden. Die Sache muß ihnen aber doch nicht ganz richtig vorgekommen sein; denn Amosis kehrte noch einmal zurück, diesmal begleitet von Imuthus, dem Vorgesetzten der Pastophoren, und einer Anzahl von anderen Beamten, und zwar am späten Abend. Bei Fackellicht drangen sie mit Gewalt in das Heiligtum ein, schändeten es $^{1}$ ) und schleppten den Ptolemäus weg. Was sie nicht mitnahmen, legten sie unter Siegel. Am folgenden Tage, dem 17. Thot, kamen sie am frühen Morgen wieder zurück, um nun noch alles, was am Abend zuvor versiegelt zurückgelassen worden war, zu konfiszieren. Dabei vergriffen sich die Beamten nicht nur an dem Besitze des Ptolemäus, sondern sie nahmen auch das, was die andern «ázo\%ot deponiert hatten, weg. Einer, der seinen Geldkrug in den Händen der Beamten erkannte, wollte ihn an sich nehmen, erreichte aber weiter nichts, als daß man auch ihm das Seine konfiszierte. Die Beamten drangen nun auch in das Adyton der Astarte ein, das nur mit genauer Not der Verwüstung entging. Die xároyot hatten schließlich nur noch ein paar Bleibecher behalten, die wegen ihres geringen Wertes offenbar von den Beamten zurückgelassen worden waren. Dagegen hatten diese ein ehernes Opferbecken, das zum Heiligtum gehörte, ebenfalls mitgenommen. Auf die Frage, was sie wollten, hatten die Beamten die

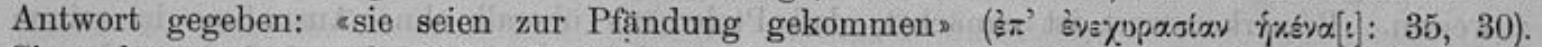
Sie nahmen nun auch noch die bleiernen Becher weg und übergaben sie dem Thürhüter Kephalas²).

Die Hauptrolle bei diesem Verfahren spielt, wie es scheint, der Vorsteher der Pastophoren, Phylis, der das Eigentum bis auf die letzten wertlosen Gegenstände wegpfänden läßt. $\mathrm{Da} ß$ es sich nicht bloß um ein Vorgehen gegen Ptolemäus handelte, scheint dadurch sicher

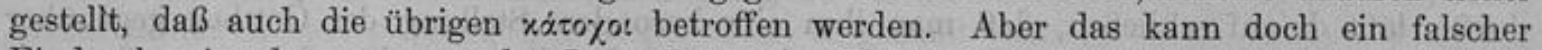
Eindruck sein, den man auș der Darstellung des Ptolemăus gewinnt. Denn bei der Wegnahme der Depositen der andern wird die Pfändung in einem besonderen Falle erst dann durch Versiegelung vollzogen, als der Betreffende sich gewaltsam wieder in den Besitz des Seinen zu setzen versuchte. Da Ptolemäus als seinen Anwalt dem König gegenüber einen gewissen Demetrius, den Sohn des Sosus, einen Kreter, also Nichtägypter, bezeichnet, scheint es sich auch hier um eine Maßregel der Ägypter gegen die Fremden zu handeln. Sie ist vielleicht von dem Vorstande der Pastophoren ausgegangen, weil Ptolemäus und andere in dem Pastophorion wohnten und daher Reibungen mit den ägyptischen Pastophoren hier am ersten stattfinden konnten. Daß Ptolemäus zu dem Kollegium der Pastophoren gehört habe und darum dem Vorsteher dieses Kollegiums unterstellt gewesen sei, läßt sich also hieraus nicht folgern.

Dagegen lassen sich einige andere Beobachtungen dieser Eingabe entnehmen, die zur Beurteilung nicht unwesentlich erscheinen. Das eine ist die, daß die xóro\%or Gelegenheit gehabt haben müssen, Geld zu verdienen. Schon oben (S. 10) ist darauf hingewiesen worden; daß die Angehörigen des Hephästion von diesem eine Unterstützung erwarteten; daß sie also doch Grund zu der Meinung haben mußten, es werde ihm möglich sein, etwas zu verdienen. Dasselbe wird durch die zuletzt besprochenen Urkunden bestätigt. Nicht nur, daß Ptolemäus selbst Geld besaß, auch der Besitz der andern wird uns bezeugt. Dennoch heißen sie $\pi \tau \omega$ yoí.

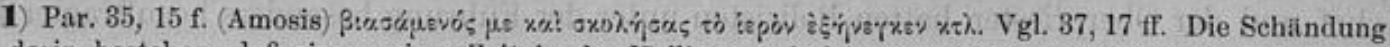
kann nur darin bestehen, daß sie zu einer Zeit in das Heiligtum eindringen, wo es verboten war, dies zu betreten, wenn ein solches Verbot nicht uberhaupt bestand. Letzteres ist nicht anzunehmen, da es sich ausdrücklich um Kultbeamte handelte. Wurden zur Nachtzeit bestimmte Teile des Kultes ausgeubt, so ist der Ausdruck vollig begreiflich. - 2) Es war mit dieser einen Affaire nicht zu Ende. Daß auch spater noch ahnliche Belistigungen stattfanden, beweist die Eingabe ans dem J. 161, die im Lond. XLIV erhalten ist. Hier wird ausdrücklich (Z. 14) die Nationalitit als Grund angegeben. 


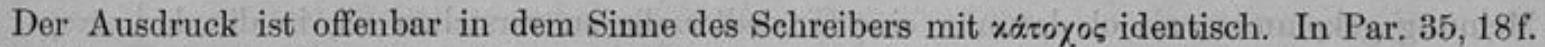

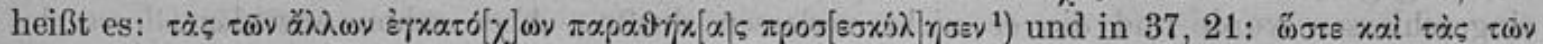

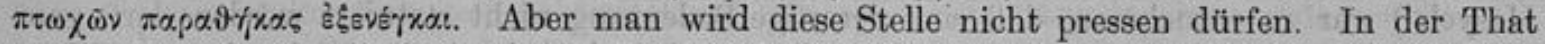
waren diese Leute offenbar, wie das Beispiel des Hephästion zeigt, großenteils arme Schlucker. Ptolemäus braucht den Ausdruck dann absichtlich, um das Verfahren der angeschuldigten Tempelbeamten in einem noch unvorteilhafteren Lichte erscheinen zu lassen.

Endlich ist noch eine andere Eigentümlichkeit der $x a \tau 0 \% \dot{\eta}$ bemerkenswert. In seiner Eingabe an den König sagt Ptolemäus (Par. 35, 34ff.), er möge, wenn es ihm gut scheine, den Kreter Demetrius, den Sohn des Sosus, vor sich kommen lassen, der die Verantwortung des Ptolemäus übernehmen werde. Dabei ist an die Eröffnung eines förmlichen Gerichtsverfahrens gedacht, bei dem die beiden Parteien einander gegenüber gestellt werden. Sein eigenes Nichterscheinen bei dieser Verhandlung erklärt Ptolemäus damit, daß es ihm unmög. lich sei, weil er sich in der $\alpha a \tau \% \chi \dot{\eta}$ befinde. Durch sie muß ihm also die Möglichkeit genommen gewesen sein, mit dem König oder überhaupt mit der Außenwelt direkt zu verkehren. Dafür, daß dem жáro\%os nach dieser Seite hin bestimmte Schranken auferlegt waren, haben wir auch noch andere Zeugnisse.

Im Jahre 160 richtete Ptolemäus eine Eingabe an den König und die Königin wegen eines Grundstückes, das er in seinem Heimatdorfe Psichin in dem herakleopolitischen Nomos hatte ${ }^{2}$ ). Seine Nachbarn hatten sich über Haus und Hof hergemacht ${ }^{3}$ ), das Mobiliar sich angeeignet, den Hof und einen unbebauten Platz dabei rings umbaut und das ganze Besitztum als ihr Eigentum angesehen. Sie hatten sich das herausgenommen, eweil ich nicht aus dem Heiligtum herausgehen und an Ort und Stelle sie zur Verantwortung ziehen darf (Par. 35, 15 ff.). Er bittet daher, die Ortsbehörden anzuweisen, daß die Angeschuldigten den Platz dem jüngeren Bruder zurückgeben und den Materialschaden in der Höhe von zwanzig Talenten ersetzen, edamit ich das Nötigste habe, um nicht vor Hunger umzukommen». In einem andern, im wesentlichen gleichlautenden Bittgesuch vom Jahre 161 (Par. 39) spricht Ptolemäus am Schluß die Erwartung aus, daß man seine Nachbarn zur Strafe zwingen werde, durch Brotlieferungen für seinen Unterhalt aufzukommen: In der zweiten Eingabe vom Jahre 160 ist diese Forderung etwas versteckter ausgesprochen (Par. 38, $28 \mathrm{ff}$.). Auch

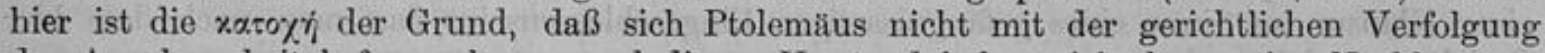
der Angelegenheit befassen kann, und diesen Umstand haben sich dann seine Nachbarn zu nutze gemacht.

So wird auch die an sich auffallende und zu falschen Schlüssen über das. Wesen

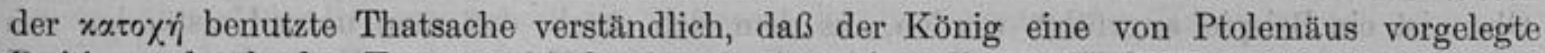
Petition edurch das Fenster hindurch versiegelt (Lond. XXXV [XIII], 5) ${ }^{4}$ ). Direkt mit dem Könige in Verbindung zu treten, war dem Petenten, wie gezeigt wurde, nicht möglich. Er hat es also, da er für seine Schützlinge endlich etwas durchsetzen wollte - es handelt sich um die Lieferungen von Öl, die den Zwillingen einbehalten worden waren - auf dem Wege gemacht, daß er dem Könige durch ein Fenster die Petition übergab, die dieser untersiegelte, womit er ihre Erfüllung aussprach.

Es kann daher nicht auffallen, wenn wir zu verschiedenen Malen hören, daß von den xároxo: der Tempelbezirk nicht verlassen wird (Par. 38, 15. 39, 10; vgl. 24, 8. 37, 4). Der Ausdruck wechselt zwischen ispóv und $\pi \alpha \sigma \tau o \varphi ̧ o ́ p t o v$, die beide als ungefähr gleichbedeutend hierdurch nachgewiesen werden. Indem man den Ausdruck ra.otop̣ópiov preßte, ist man zur

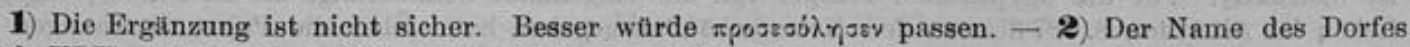
steht Lond. XLV, 7 (Kenyon, p: 36); er ist nicht mehr lesbar Par. 38, 6, wo nur noch die Endung .... (v) zu

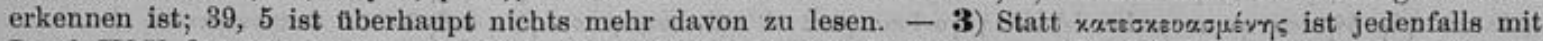

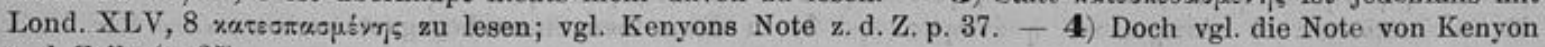
z. d. Zeile (p. 25). 
Meinung gekommen, als ob darunter eine Einsiedlerzelle zu verstehen sei, in die der xd́ro\%os eingeschlossen wurde und die er nicht verlassen durfte. Aber schon aus der Glosse des Hesych ${ }^{1}$ ) war $\mathrm{zu}$ entnehmen, daß eine derartige Bedeutung nicht statuiert werden darf, ganz abgesehen davon, daß das Wort hier durch das parallele ispóv in einer ganz bestimmten Weise erläutert wird. Gemeint ist damit der gesamte Tempelbezirk, der für jedes einzelne Heiligtum wieder für sich abgeschlossen war. Bei der riesigen Ausdehnung, die das Sarapeum hatte

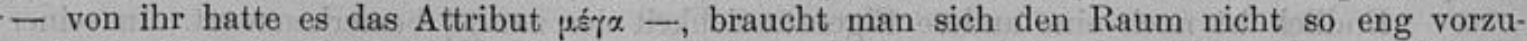
stellen. Die einzelnen Heiligtümer enthielten nicht nur das eigentliche Tempelgebäude, sondern in Verbindung mit ihm andere Gebäulichkeiten, die den Priestern und dem übrigen Kultuspersonale zur Wohnung dienten und wohl überhaupt alles einschlossen, was der Kult an Gerätschaften u. s. w. erforderte ${ }^{2}$ ). Derartige Nebengebäude hat Strabo in Heliopolis noch gesehen. Die Fremdenführer, die ihm als Erklärer der verlassenen Herrlichkeit dienten, berichteten ihm, daß hier einst die weisen und sternenkundigen Priester gewohnt hätten. Damals aber zeigte sich in den verödeten Räumen niemand mehr, als einige Opferpriester und Fremdenführer ${ }^{3}$ ). Derartige vielräumige Gebäulichkeiten werden wir uns auch in dem großen Sarapeum bei Memphis vorzustellen haben.

Innerhalb dieses Bezirkes war ein freier Verkehr möglich. So konnte Ptolemäus, der

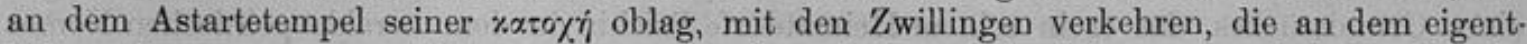
lichen Sarapeum angestellt gewesen zu sein scheinen. So hören wir, daß der Bruder des Ptolemäus, Apollonius, der sich ebenfalls als xátoxos in dem Sarapeum aufhält, gelegentlich eines Ganges zu dem Pastetenbäcker, der sich mit seinem Geschäft ebenfalls in dem Heiligtume befand und bei dem er Fleischpasteten einkaufen wollte, in einen Streit geriet. Der Verkäufer wollte ihm minderwertige Ware aufhängen, die er erst nach einigem Zögern durch bessere ersetzte. Als aber Apollonius wieder in seiner Wohnung war - in

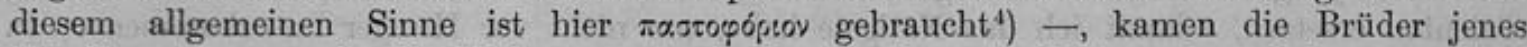
Hăndlers, drangen in die Wohnung ein und prügelten Apollonius ohne Scheu vor dem Heiligtum, in dem sie sich befanden, und ohne Acht auf Anstand und gute Sitte durch, nahmen noch dazu das Geld, das sie fanden, weg (Par. 40). Auch hier liegt vielleicht ein Ausbruch der Spannung vor, die zwischen den Ägyptern und den Fremden bestand. Von einer Klausur im Sinne eines gefängnisartigen Eingeschlossenseins darf man nach dem hier Berichteten nicht reden.

Apollonius tritt uns in dem eben besprochenen Gesuche in einer Eigenschaft entgegen, in der wir ihn auch sonst kennen lernen: nämlich als Haushalter seines Bruders Ptolemäus. Oben ist ein Beispiel angeführt worden, aus dem sich ergab, daß man unter Umständen von den жd́rtoyot erwartete, sie ließen ihren Angehörigen zu Hause eine Unterstützung zu teil werden. Das war aber nicht die Regel; vielmehr mußten bei länger dauernder $x x \tau 0 \times \dot{\eta}$, die nicht allzu selten gewesen zu sein scheint, die Betreffenden von Hause aus Zuschüsse erhalten und scheinen dann meist sich zusammengethan zu haben, um einen gemeinsamen Haushalt zu führen. So bittet Ptolemäus 161 den König in einem leider nur stark verstümmelt erhaltenen Briefe, er möge seine Brüder vor den Chikanen der Ortsbehörden schützen, da er von ihnen,

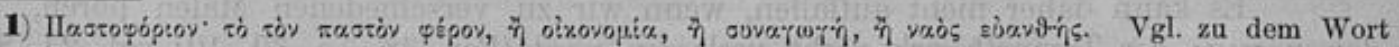
Deißmann, Bibelstudien (Marburg 1895), S. 145 f. - 2) Man kann sich, um ein Bild von der Beschaffenheit soleher Anlagen zu gewinnen, an die Tempelbauten von Jerusalem erinnern. Vgl. Stade, Geschichte des Volkes Israel (Berlin $1887 \mathrm{ff}$ ), I, S. $326 \mathrm{ff}$.; II, $48 \mathrm{ff}$. Namentlich der II, 51 mitgeteilte Grundriß des Tempels Ezechiels ist instruktiv. Für die ägyptischen Tempel vgl. die eingehende Schilderung, die A. Erman, Ägypten u. alg. Leben im Altertum, S. $887 \mathrm{ff}$, von den Nebengebiuden gegeben hat. Utber die Priesterwohnungen S. 388. -

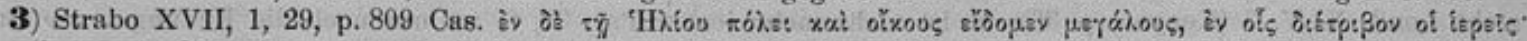

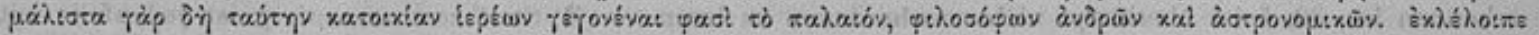

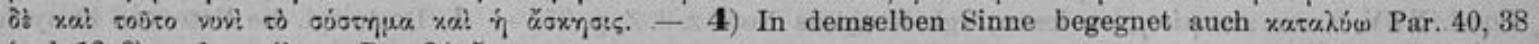

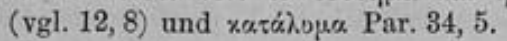


die ihm sein Brot lieferten, erhalten werde (Par. 39, 14). Auf einen andern jüngeren Bruder des Ptolemäus, den Apollonius, bezieht sich auch das Gesuch, das jener 162 an den Unterkassenverwalter Sarapion richtete (Lond. XXI [V]). Er hatte in einem früheren Gesuch seinen Bruder der Fürsorge des Beamten empfohlen und ihn als den bezeichnet, der für den Unterhalt zu sorgen habe ${ }^{1}$ ). Nun aber sei sein Bruder von ihm weggerissen worden und könne sich daher auch der Zwillinge nicht mehr annehmen (Lond. XXI [V], 20 ff.). Der Zusammenhang ist nicht mehr ganz deutlich zu erkennen. Jedenfalls ist soviel sicher, daß Ptolemäus durch jenen Umstand selbst Schaden erlitten hat und daß er um eine Anweisung an den Verwalter

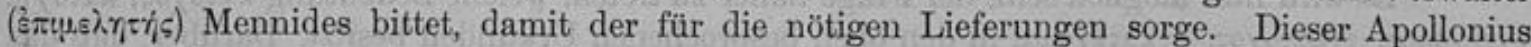
ist jedenfalls derselbe, den wir 156 als xdxco 0 s im Sarapeum finden und der in diesem Jahre sich bei dem Strategen Posidonius wegen der oben mitgeteilten Mißhandlungen, die er von den Brüdern des Pastetenbäckers erfahren hat, beklagt. Auf diesen Bruder bezieht sich auch das interessante Gesuch des Ptolemäus, das in Lond. XXIII (II) erhalten ist. Das Gesuch stammt aus dem Jahre $158 \mathrm{v}$. Chr. Ptolemäus berichtet darin, daß sein Vater in den Zeiten des Bürgerkrieges sein Leben verloren und den Bittsteller mit seinem jüngeren Bruder zurückgelassen habe. Er selbst befinde sich bereits 15 Jahre in der \%arox $\eta$ und sei nun, weil er kinderlos sei, gezwungen, seinem Bruder zu einer militärischen Stelle zu verhelfen, damit er selbst sich als жároð0 anständig durchschlagen könne. Er bitte daher mit Rücksicht auf die lange Dauer seiner $x$ жо $\chi \eta^{\prime}$ seinen Bruder in die Compagnie des Dexilaus einzureihen und ihm den Sold und die Rationen zu geben, die die andern Soldaten erhielten. Es scheint, daß der Bruder gewissermaßen nur à la suite geführt werden soll und daß die ganze Sache nur ein Scheinact ist, durch den sich Ptolemäus ein festes Einkommen verschaffen will. Soviel geht jedenfalls daraus hervor, daß die beiden Brüder hier in einem gemeinsamen Haushalte zusammen lebten ${ }^{2}$ ).

Nicht ganz deutlich ist die Rolle, die ein gewisser Harmais ${ }^{3}$ ) spielt (Lond. XXXIV ${ }^{\mathrm{r}}[\mathrm{XV}]$ ). Er richtete an den Strategen Dionysius ein Gesuch, ihm gegenüber einer Frau aus Memphis, deren Töchterchen Tathemis im Sarapeum weilte, und für das die Mutter 1300 Drachmen bei ihm hinterlegt hatte, zu seinem Rechte zu verhelfen. Jene Frau, Nephoris mit Namen, habe ihm das Geld wieder abgenommen, um es für die Beschneidung und Ausstattung ihrer Tochter zu verwenden; wenn sie das bis zu einem gewissen Zeitpunkte nicht gethan hätte, werde sie ihm die Summe zurückgeben. Aber weder das eine, noch das andere sei geschehen. Die Tochter verlange nun das Geld von ihm, und er sei daher in arger Bedrängnis. Was dieser xd́royos mit dem Aufenthalte der Tathemis im Sarapeum zu thun hatte, ist nicht deut. lich zu erkennen. Bemerkenswert ist übrigens die Bemerkung des Harmais, daß er vom

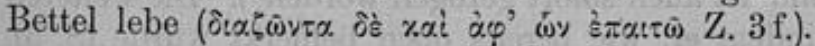

Aus dem im vorstehenden Erörterten ergiebt sich ein im ganzen ziemlich deutliches

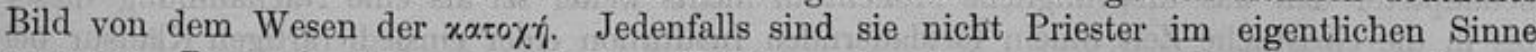
gewesen. Dennoch stehen sie mit dem Heiligtum in einer so engen Beziehung, daß man ihnen eine Wohnung in den mit den Heiligtume verbundenen Gebäulichkeiten anwies. Die Gründe, die den einzelnen zur жaro $\chi \dot{y}$ trieben, konnten recht verschieden sein; in den uns erhaltenen Dokumenten war es in einem Falle, wie es scheint, eine lebensgefährliche Krankheit, in andern vielleicht Armut. Die Dauer hing von dem Belieben des einzelnen ab; lange Dauer gab dem Betreffenden ein gewisses Ansehen und unterstützte seine Bitten. Der жd́toxos

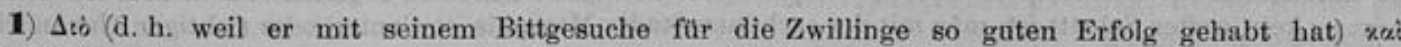

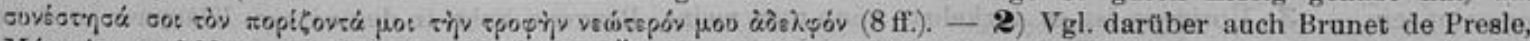
Mémoire, p. 566 ss., wo auch (p. 567 s.) eine Übersetzung des auf dieselben Verhältnisse gehenden vatikanischen Papyrus (Mai, Classici auctores V, p. 552 sqq.) gegeben ist. Doch hat Brunet im einzelnen manches schief dargestellt. - 3) Brunet de Presle, Notices p. 293 n. 3 nimmt an, daß der Par. 85,19 genannte mit dem obigen identisch ist. Wahrscheinlich hat er darin recht. 
war an das Heiligtum gebunden und unterlag in seinem Verkehr mit der profanen Außenwelt bestimmten Beschränkungen. Den Tempelbezirk durfte er jedenfalls nicht verlassen. beweisen die der Umstand, daß einer Klagen über die Not, die Bezeichnung der «.́. recht traurig war.

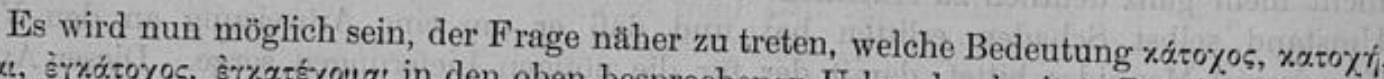

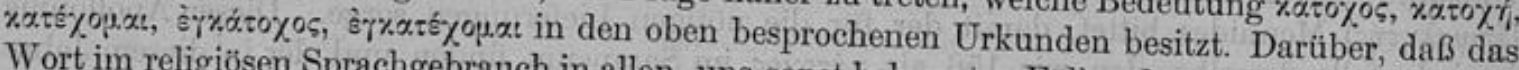
Wort im religiösen Sprachgebrauch in allen, uns sonst bekannten Fällen den von Gott Besessenen, den Inspirierten bezeichnet, besteht kein Zweifel, und es hat keinen Zweck, für diese Bedeutung und keiner andern Beiben ${ }^{1}$ ). Daß das Wort in Ägypten noch in der späteren Zeit in dieser belegen ${ }^{2}$ ). Dennoch hat gehen und eine andere aufstellen sur quelques Papyrus lingues et mussen. Reuvens ist in seinen Lettres à M. Letronne behauptet hat, daß man dieser Bedeutung nicht gegenüber den aus Memphis stammenden Dokumenten mit dieser Bedeutung nicht auskomme ${ }^{3}$ ). Seine Argumentation schien so einleuchtend, daß sich alle, die sich eingehend mit diesen Schriftstücken befaßt haben, von ihm haben überzeugen

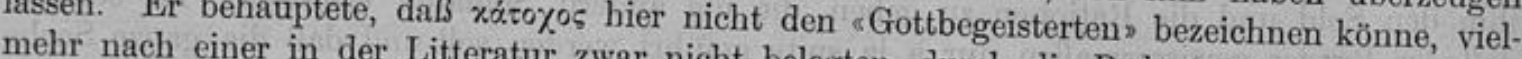

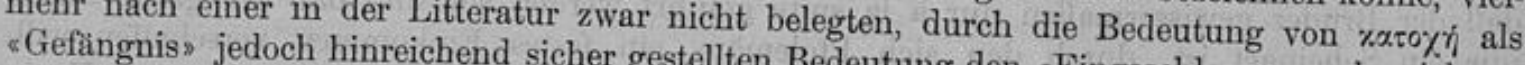
müsse. Für eine spricht der erste

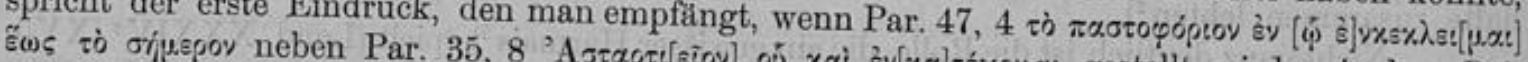

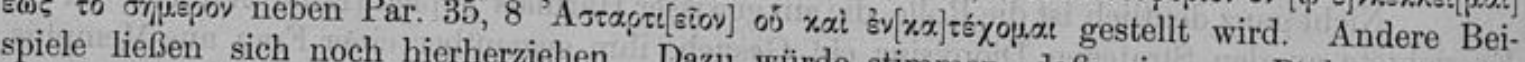
den andern жxroyo: wion stimmen, daß wir von Ptolemäus und also hier von die in Verbindung mit einzigartigen, uns anderweitig durchaus nicht bekannten Institution, zur Bildung yon Einsiedlergenosenschulte stand, Kunde erhalten. Danach hätte dieser Kult welt, ein Leben in strengster Kenschaften geführt, die, völlig abgeschlossen von der Außenschlossen waren, und die in Velausur führten. Sie lebten in Zellen, in denen sie eingeVerkehr mit der Außenwelt fand mit dem christlichen Mönchtum nur durch die Fensteröffnung der Zelle statt. Die Parallele Folgerungen daraus zog dan lag nahe und ist auch sofort gezogen worden $\left.{ }^{4}\right)$. Die weiteren behauptete, daß das ursprünglingarten, indem er, wie bereits oben bemerkt wurde (S. 3), bis in die christliche Zeit hinein Mönchtum nichts weiter sei als eine Nachahmung dieser (1)

1) Vgl die reichlichen Belege aus verschiedenen Schriftstellern, die in Stephanus' Didot'schen Ausgabe 8. v, xúroyos und Èratoysì mitgeteilt werifstellern, die in Stephanus' Thesaurus in der

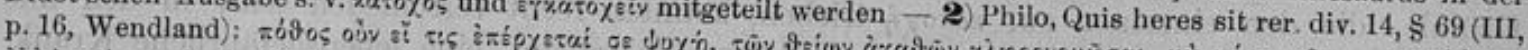

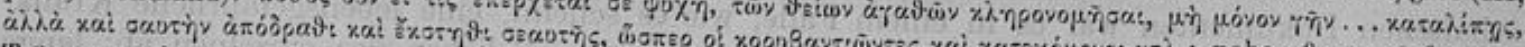

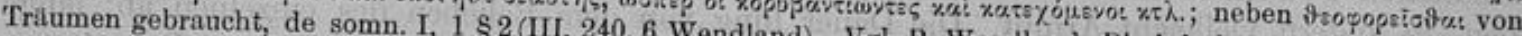
53, S.21. Rohde, Psyche 304,

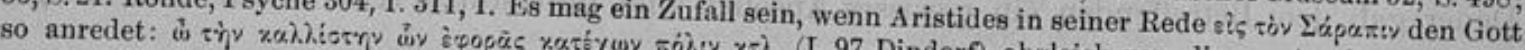
xároxo: kein weiter Sehritt ist, mag diesem Ausdruck zu den gemeint sein. - B) Uैbrigens ist es verkehrt, wenn man meint Po (so Canter) oder richtiger Alexandria (Reiske) Sinne von Mönchen gesehen. eine nicht ausreichende Vorstellung vom Wesen der Wortes veranlaßt. Seine Nachfolger baben leider der Hierodulie hat ihn zu einer falschen Übersetzung des - 4) Brunet de Presle, Mémoire, p. 564. Reuvens hatige ganz übersehen und das Falsche noch ubertrieben. 
den Sarapisheiligtümern. Und es schien sich gut zu treffen, daß auch von einem christlichen Einsiedler berichtet wird, er habe mit der Außenwelt durch das Fenster seiner Zelle verkehrt $^{1}$ ), genau, wie Ptolemäus von sich sagt, er habe seine Bittschrift dem Könige «durch

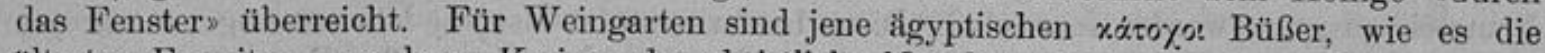
ältesten Eremiten, aus deren Kreisen das christliche Mönchtum hervorgegangen ist, gewesen sein sollen.

Aus dem oben ermittelten Zustand vom Leben der xátoðo: ergab sich, daß diese Auffassung jedenfalls beträchtlichen Korrekturen unterliegt. Von einer Klausur in dem Sinne, wie sie Reuvens und die ihm folgenden Gelehrten annahmen, kann keinesfalls die Rede sein. Mit den Priestern hat Ptolemäus nicht durch das Fenster verkehrt (Lond. XXI [V], 4 ff.). Davon, daß die жázo/ot «Büßer» waren, steht in den Urkunden nichts zu lesen ${ }^{2}$ ); vielmehr

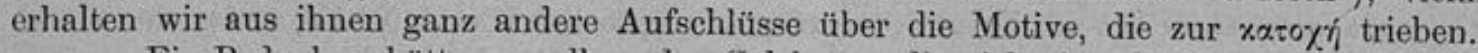

Ein Bedenken hätte vor allem den Gelehrten, die sich über die Frage geäußert haben, kommen müssen: nämlich, wie es sich erklärt, daß wir bei denen, die sich über die ägyptische Religion ausgelassen haben und die sich doch zum Teil nicht schlecht über sie unterrichtet zeigen, so gar nichts über diese gewiß auffallende Art der Gottesverehrung vernehmen; ja, daß ein solcher asketischer Zug nicht zu den Eigentümlichkeiten der ägyptischen Religion gehörte ${ }^{3}$ ). Ferner, daß mit einer einzigen Ausnahme die zahllosen Inschriften, die von der Verbreitung des Sarapis- und lsiskultes in den Ländern des römischen Kaiserreiches Kunde geben ${ }^{4}$ ), von diesem Institut nichts wissen. Hier werden $\vartheta s p a \pi \varepsilon u \tau a i$ genannt, Priester

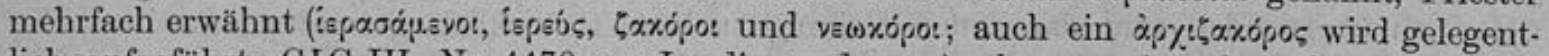

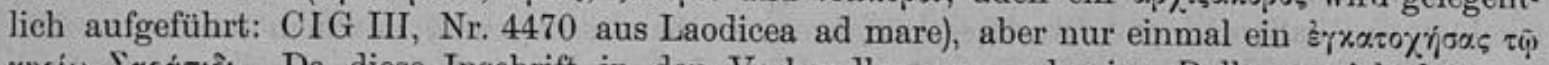

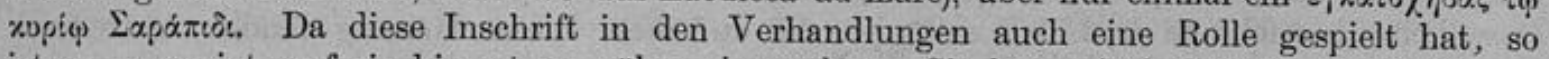
ist es angezeigt, auf sie hier etwas näher einzugehen. Sie lautet (vgl. CIG II, Nr. 3163):

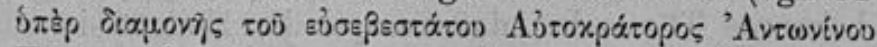

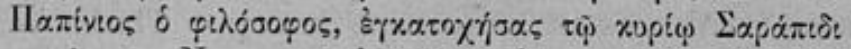

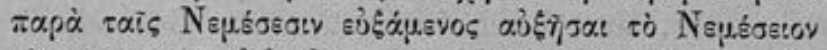

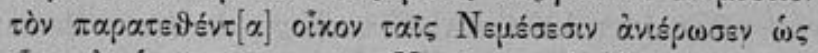

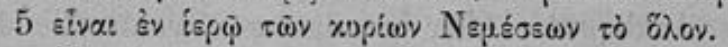

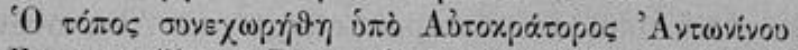

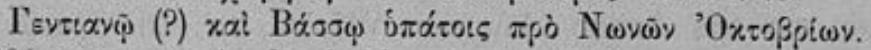

Diese Inschrift stammt, wie die beiden letzten Zeilen ausweisen, aus dem Jahre 211, in dem Gentianus und Pomponius Bassus Konsuln waren. Sie enthält die.Schenkung eines Philosophen Papinius an das Heiligtum der Nemeseis in Smyrna, bestehend in einem Hause,

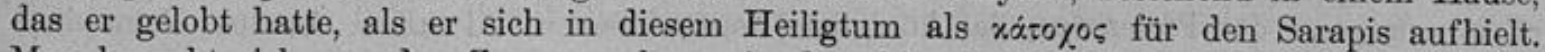

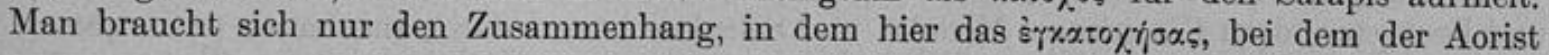

1) Palladius, Hist. Laus. 43, 6. Den kritischen Text s. in meiner Schrift: Palladius und Rufinus (Gießen 1897), S. 100, 6. - 2) Daher ist es auch durchaus nicht angebracht, den Bericht, den Chaeremon in seinen Aegyptiaca von der Askese der agyptischen Priester gegeben, und den Porphyrius, De abstin. IV, 6 sqq. ausgeschrieben hat, auf die xároyo: zu beziehen. Über die Glaubwürdigkeit des Chaeremon hat sich Strabo XVII, 1,29 , p. 806 wenig günstig gelußert. Und wenn in dieser Darstellung auch einiges Richtige enthalten wäre, so gilt das doch nur von den Priestern, nicht den xároxo:. Die Chaeremonstelle bei C. Müller, Fragmenta histor. Graec. III (Paris 1849), p. 497 sq. - 3) Flinders-Petrie, Religion and Conscience in Early Egypt (Lond. 1898), p. $122 \mathrm{f}$ - - 4) Vgl. die außerordentlich sorgfaltigen Zusammenstellungen, die W. Drexler, Der Isis- und Sarapiskult in Kleinasien (Numismat. Zeitsehr. XXI [Wien 1889], S. 1-234) und Mythologische Beitrilge I, Der Kultus der igypt: Mythologie in den Donaulindern (Wien 1890) gegeben hat. Recht selten sind die Zeugnisse für Germanien. Doch ist jetzt in Stockstadt a. M, bei den Limesausgrabungen ein dem Sarapis und der Isis errichteter Altar gefunden worden; die Inschrift ist veröffentlicht von E. Anthes, Darmst. Zeitung 1898, Nr. 246. Vgl. Zur Geschichte des Mainthals in der Römerzeit (Aschaffenburg 1899), S. 12; dem Separatabdruck dieses Vortrags ist eine $\mathrm{A}$ bbildung des Steines beigegeben; ferner Zangemeister in dem Korrespondenzbl. d. Westdeutschen Zeitschrift 1898 , Nr. 12 , S. 97. 
doch sicherlich nicht ohne Absicht gebraucht ist, zu vergegenwärtigen, um die Unmöglichkeit der herkömmlichen Deutung des Wortes einzusehen. Es ist in der That schlechterdings nicht zu begreifen, wie eine derartige Klausur zu Ehren des Sarapis in einem Heiligtume der Nemeseis ausgeübt worden sein sollte. Diese Inschrift stützt also die Übersetzung von xáro\%o૬ nicht im geringsten, vielmehr wirft sie sie völlig über den Haufen $\left.{ }^{1}\right)$. Es genügt, sich an jenen Hephästion zu erinnern, von dem oben die Rede war (S. 9 f.). Er suchte das Heiligtum auf, weil er aus einer großen Gefahr, einer schlimmen Krankheit Rettung suchte. Es wird auch bei dem Philosophen Papinius, der im Jahre 211 den Nemeseis seine Dankbarkeit für erfahrene Hülfe durch Schenkung eines Hauses bezeugt, kein anderer Grund gewesen sein,

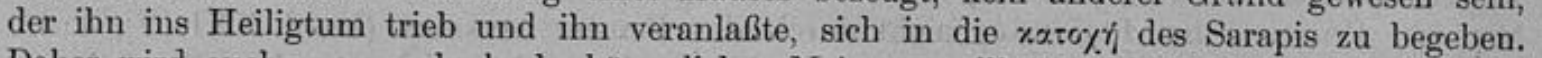
Daher wird auch, was nach der herkömmlichen Meinung völlig unerklärlich bleiben muß, von

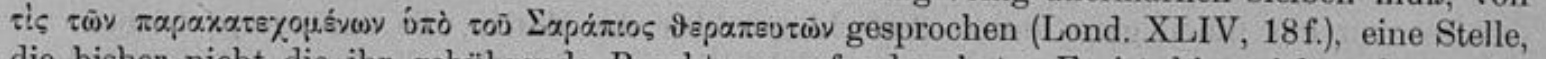
die bisher nicht die ihr gebührende Beachtung gefunden hat. Es ist hier nicht schwer einzusehen, daß man mit der Übersetzung reclusus nicht auskommt: denn wie sollte sie Sarapis eingeschlossen haben? Gemeint kann nur ein von Sarapis «Besessener, $\operatorname{sein}^{2}$ ).

Unter xázoxo: haben wir daher die Bezeichnung für diejenigen Personen zu erblicken, die das Heiligtum des betreffenden Gottes aufsuchten, um durch Incubation von ihm eine Hülfe zu erfahren. Die Vorstellung, die dabei zu Grunde liegt, ist die, daß der Betreffende bei der Incubation von der Gottheit ergriffen wird. Nachdem die Gottheit von ihm Besitz genommen hat, ist sie im stande, die feindlichen Dämonen, die in ihm die Krankheit hervorriefen, zu überwinden und damit den Heilung suchenden wirklich gesund zu machen. Es leuchtet ein, daß man ein derartiges Verfahren durchaus sachgemäß mit dem Ausdruck ${ }^{\circ} \mathrm{Be}$ sessenheit, bezeichnete und daß sich die, die auf diese Weise Heilung fanden, zutreffend -Besessenes nennen konnten ${ }^{3}$ ).

Es ist eine bekannte Thatsache, daß Sarapis der Heilgott ist und als solcher häufig mit Asklepios identifiziert wird. Es ist weiter eine bekannte Thatsache, daß Sarapis häufig in Anspruch genommen wurde, um durch Incubation zur Gesundheit zu verhelfen ${ }^{4}$ ). Um das genauer auszuführen, wozu hier kein Anlaß vorliegt, bedürfte es einer weitläufigen Vergleichung mit dem Kulte des Asklepios. Hier genügt es, wenn die Hauptpunkte kurz zusammengestellt werden. Daß man den Sarapis befragte, als Alexander der Große auf dem Totenbette lag, wissen wir aus Arrian (Anabasis VII, 26,2). Die Quelle ist so unverdächtig wie möglich. Denn Arrian benutzte für diese Partien, wie Wilcken gezeigt hat ${ }^{5}$ ), die

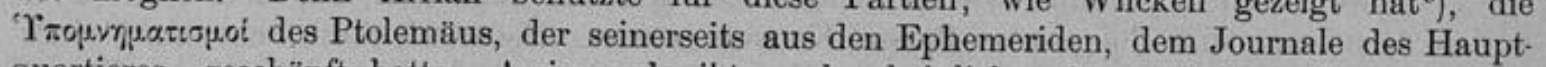
quartieres, geschöpft hatte. Arrian schreibt, wahrscheinlich mit wörtlichem Citat aus den "Erinnerungen» des Ptolemäus, das königliche Journal berichte, Peithon, Attalus, Demophon

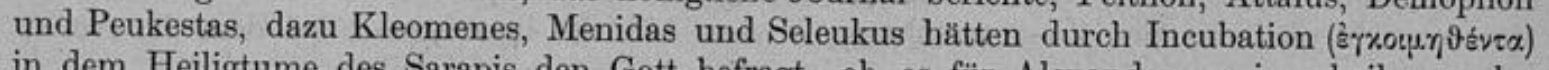
in dem Heiligtume des Sarapis den Gott befragt, ob es für Alexander weniger heilsam oder besser wäre, wenn er sich in das Heiligtum des Gottes bringen ließe und bitte, sich vom Gotte heilen zu lassen. Darauf sei die Antwort von dem Gotte gekommen, er solle sich nicht ins Heiligtum bringen lassen, sondern wenn er dort bleibe (wo er sei), werde es besser

1) Vgl. Bestmann, Geschichte d. christl. Sitte I (Nördlingen 1880), S. 128 Anm. - 2) Wie Wessely die Ubbersetzung cein Klausnerdiener des Sarapenms» philologisch rechtfertigen will, ist mir unklar (Wiener Studien, 1886, S. 204). - 3) Es ist sehr instruktiv, zu beobachten, unter welchen Gesichtspunkten sich ein Mediziner die Vorgänge bei der Incubation deutlich macht. Stoff genug dazu bieten die lspo: $\hat{b}^{\prime} ; 0:$ des Aristides. Eine Beurteilung vom Standpunkt des Mediziners findet sich in G. Ritter von Rittershain, Der medizinische Wunderglaube u. d. Incubation im Alterthume (Berlin 1878), S. $78 \mathrm{ff}$. Danach ist der Ausdruck « Besessenheits durchaus verständlich, wenn ihn auch Rittershain nie gebraucht. - 4) Vgl. Chr. Petersen in Ersch u. Gruber, Allgem. Encyklopadie d. Wissensch. u. Künste I, 82, S. 341, und vor allem die stoffreichen Artikel "Asklepios in Rosehers Lexikon d. griech. u. rómischen Mythologie und in Pauly-Wissowas Real-Encyklopädie d. klass, Altertumswissenschaft, beide von E. Thrảmer. - 5) Philologus 53 (N. F. 7, Göttingen 1894), S. $118 \mathrm{ff}$. 
für ihn sein. Das hätten die Gefährten gemeldet und bald darauf sei Alexander gestorben ${ }^{1}$ ). $\mathrm{Da}$ dieser Bericht auf den offiziellsten Quellen beruht, so ist er für die Beurteilung dieser wichtigen Seite des Sarapisdienstes von unschätzbarem Wert. $\mathrm{Er}$ beweist, daß man die Incubation bei dem Heiligtum des Sarapis zu einem doppelten Zweck kannte: einmal, um von dem Gott Orakel zu erhalten, sodann um Heilung bei ihm zu finden. Beides ging wohl in der Regel miteinander Hand in Hand. Wie groß das Ansehen dieses Orakels in Babylon war, ergiebt sich daraus, daß die Freunde Alexanders zu diesem Mittel griffen, um das Geschick von ihrem Herrn abzuwenden.

Wie in dem Asklepioskult, so ist die Sitte des Tempelschlafes von dem Sarapiskulte auch sonst vielfach bezeugt. Strabo berichtet (XVII, 1, 17, p. 801 Cas.) von dem Sarapeum in Kanobus, das in großen Ehren stehe, weil es Heilungen bewirke, so daß die verständigsten Leute an diese Heilkräfte glaubten und in dem Tempel für sich oder für andere schliefen. Einzelne schrieben auch die Heilungen auf, andere die Erfolge der dort erteilten Orakelsprüche $^{2}$ ). Das ist Zug um Zug dasselbe Bild, das wir von dem Sarapiskulte in Babylonien durch die Notiz aus den Ephemeriden Alexanders erhalten. Daher ist ein großer Teil der Inschriften, die eine Schenkung an Sarapis erwähnen, ihm aus dem Grunde gesetzt, daß man ihm für eine glücklich vollzogene Heilung danken wollte ${ }^{3}$ ). In demselben Sinne spricht Aristides von den "Träumen", die er auf Asklepios und Sarapis zurückführt ${ }^{4}$ ); er wird allgemein sder Helfers genannt, alles kommt durch ihn und um seinetwillen uns zu, was wir uns nur wünschen ${ }^{5}$ ); für Seele, Leib und alle Bedürfnisse des Lebens sorgt er. Darum wird er auch von allen, von Königen und von Privatleuten, von Weisen und Unweisen, von Vornehmen und Geringen, von Guten und Bösen in Ehren gehalten ${ }^{6}$. Es ist hier nicht nötig, die Beispiele noch zu vermehren, da aus den angeführten schon die Sitte der Ineubation bei den Heiligtümern des Sarapis und die große Beliebtheit, die sie genoß, genügend deutlich ist.

Für das weitere wird es nützlich sein, den Ursprung dieser Sitte noch kurz zu betrachten. Daß sie sich, wie bei Sarapis, so auch bei Asklepios bezeugt findet, wurde bereits oben betont. Um sich ihr Wesen deutlich zu machen, empfiehlt es sich, von den semitischen Religionen auszugehen, da wir hier durch das Alter der Quellen die ursprünglichen Formen noch besonders deutlich erkennen und die zu Grunde liegenden Vorstellungen reinlicher als sonst scheiden können ${ }^{7}$ ).

Die Grundlage bildet der für die antike Vorstellung selbstverständliche Gedanke, daß die Gottheit unmittelbar in den Lauf der Dinge eingreift und zwar, daß sie nicht allein bei den großen Entscheidungen des öffentlichen Lebens eine Rolle spielt, sondern daß auch der einzelne in seinem Leben ihr Walten verspürt und ihr Eingreifen veranlassen kann. Dieser.

1) Übereinstimmend damit, nur viel kürzer berichtet Plutarch, Vita Alex. 77, dieselbe Thatsache. -

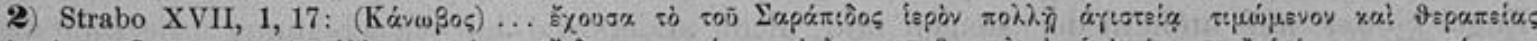

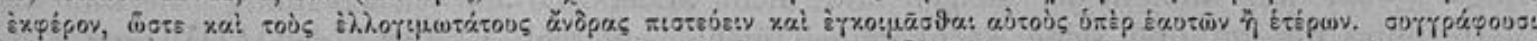

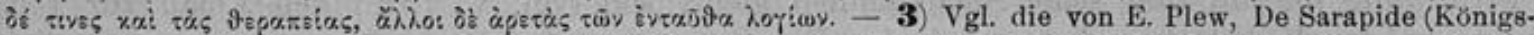
berger Dissert. 1868), p. 31 sqq. gesammelten Titel. Sie lassen sich jetzt noch beträchtlich vermehren. -4 ) Rede auf Sarapis (Dindorf I, p. 84). - 5) A. a. 0. p. 87. - 6) A. a. 0. p. 88 sq. - 7) Ich muß mich hier wesentlich an die Ergebnisse der alttestamentlichen Wissenschaft halten, da ich die Ergebnisse der assyriologischen Forschungen auf ihre Richtigkeit nicht zu prüfen vermag. Die Schnelligkeit, mit der hier die Hypothesen uber wichtige Punkte wechseln, und der Gegensatz, in dem sich die Wortführer vielfach befinden, erwecken kein besonders günstiges Vorurteil für die Sicherheit sowohl der Methode als auch der Schlüsse. Die beste Darstellung der vorprophetischen Religion Israels, die wir bis jetzt besitzen, ist die von B. Stade, Gesch. d. Volkes Israel (in Onckens Sammlung) I, $428 \mathrm{ff}$,, auf dessen Grundanschauung auch die nachfolgenden Bemerkungen beruhen. Über die griechische Sitte vgl. Schœmann, Griech. Altertümer $\mathrm{II}^{2}$, S. $318 \mathrm{ff}$; über die römische Marquardt, Handb. d. röm. Staatsverwaltung III, S. 97 ff.; E. Rohde, Psyche (Freiburg 1894), S. $113 \mathrm{ff}$. V.gl. auch den Aufsatz von G. Welcker, Incubation; Aristides d. Rhetor (Kleine Schriften III [Bonn 1850], S. 89 ff.). 
Gedanke ist speciell auf alle diejenigen psychischen Zustände übertragen worden, bei denen der Mensch irgendwie sein Bewußtsein verloren hat oder das Bewußtsein in ihm getrübt ist. Da Gott ein geistiges Wesen ist und diese Vorstellung nicht eine bloße Abstraktion war, sondern in dem Denken wirklich Leben besaß, so konnie er auch von dem Menschen geistig Besitz ergreifen, den Geist des Menschen beeinflussen, ja ihn vollständig zur Ruhe zwingen; und da die Thätigkeit des Geistes auch die des Körpers reguliert und bestimmt, so waren in einem solchen Falle auch die Funktionen des Körpers von der den Menschen gleichsam bewohnenden Gottheit abhängig. Diese Gedanken führtęn zu den Vorstellungen, daß die Krankheiten durch böse Geister bewirkt sind, daß vor allem die Geisteskrankheit auf die « Besessenheit zurückzuführen ist: Vorstellungen, die noch im Neuen Testamente vorliegen und die überhaupt in der volkstümlichen Medizin der alten Zeit so gut wie unsrer Tage - man vergleiche nur das bei dem Volke noch allgemein übliche «Besprechen» bei Krankheiten - nachgewirkt haben. Andererseits vermag aber die Gottheit auf diesem Wege dem Menschen auch helfend und fördernd zur Seite zu stehen, indem er ihm durch Träume gute Ratschläge giebt, seine Wünsche kundthut oder die Zukunft offenbart, so daß das Wort einen guten Sinn hat: ses ist umsonst für euch, die ihr frühe aufsteht, spät euch niederlegt und das Brot der Mühen eßt: ebenso giebt er's seinem Geliebten im Schlafes (Psalm 127, 2). Und neben den Besessenen stehen die "Propheten", die von Gott begeistert sind und die nicht nur, wie Samuel, dem suchenden Saul Auskunft über die verlaufenen Eselinnen geben (1. Regn. 9), sondern die auch durch die in ihnen lebendige Stimme und den Geist Gottes zum Besten des Volkes reden, wie Elia, und seine Thaten beeinflussen, wie Samuel. Dieser Einwirkung des göttlichen Geistes aber kann jeder teilhaftig werden, der sie sucht und dessen sich die Gottheit in dieser Weise annehmen will. Da man die Gottheit an die Stelle, wo sich ihr Heiligtum befindet, gebunden denkt, so ist dies der gegebene Ort, an dem eine Einwohnung des Gottes vor andern zu erreichen ist. Und daß man Traumorakel hatte, beweisen noch deutliche Spuren im Alten Testament. Hierauf ließe sich die Erzählung von dem Traume, den Samuel in dem Heiligtume zu Silo hatte, beziehen (1. Regn. 3, $1 \mathrm{ff}$.). Als einst Samuel an seinem gewohnten Platze bei der Bundeslade schlief, hörte er dreimal den Ruf: Samuel, den er von seinem Vorgesetzten, dem Priester 'Eli, kommend wähnte. Beim dritten Male wird er von diesem darauf aufmerksam gemacht, daß ihn Jahwe selbst rufe und daß er antworten müsse: Herr, rede, dein Knecht hört. Das thut denn auch Samuel und er empfängt nun eine Weissagung über den Untergang der Familie des 'Eli. Doch ist hier wohl kaum an ein Incubationsorakel zu denken, da Samuel ein Priester ist, nicht zu dem Zwecke, um die Auskunft zu erhalten, in dem Tempel schläft und wir sonst von einer derartigen Sitte in dem Heiligtume zu Silo nichts wissen ${ }^{1}$ ). Deutlich ist das besonders bei Bêth' êl, bei dem der issós hóros (Gen. 28, 11 ff.) uns noch die Kunde davon giebt. Denn der Traum, den Jakob dort hat von der in den Himmel aufragenden Leiter, auf der die Engel Gottes auf und nieder steigen und nicht anders die Jahweerscheinung, die ihm die Verheißung für ihn und seine Nachkommen giebt, soll (vgl. V. 19ff.) den Anlaß zur Entstehung der Kultstätte geboten haben. Die Sitte, den Stein, in dem man ursprünglich die Gottheit wohnend gedacht hatte, mit Öl zu salben, wird wohl der späteren Sitte bei der Incubation entsprechen. Diese Sitte hat noch bis in die Königszeit hinein bestanden, wie für Bêth-'el durch Hosea 12, 5 bezeugt ist: «Er (d. h. Jakob-Israel) kämpfte gegen eine Gotteserscheinung; er weinte und bat sie um Erbarmen; sie fand ihn in Bêth-'êl und dort redet sie mit uns $\left.{ }^{2}\right)$. Auf ein derartiges Heiligtum in Gibe ôn läßt sich schließen aus 3. Regn. 3, $5 \mathrm{ff}$., wonach sich Salomo nach seiner Thronbesteigung dorthin begab und des Nachts im Traume

1) Vgl. Stade, Gesch. d. Volkes Israel I, S. 445, wo noch andere Falle solcher Gottesoffenbarungen im Traum besprochen sind, und 476 A. 1. - 2) Der Text der Stelle steht nicht ganz fest. Die syrische Übersetzung sowie Aquila, Symmachus und Theodotion lasen imo «mit ihm». 
eine Erscheinung Jahwes hatte, bei der ihn Gott fragt, was er sich wünsehe, und er sich Verstand und Gottesfurcht erbat, um sein Volk wohl regieren zu können. Vielleicht hat ein solches Heiligtum auch auf dem Horeb bestanden und zwar in einer Höhle des Berges, wofür die Stelle 3. Regn. 19, 9 ff. zu sprechen scheint. Doch ist das unsicher $\left.{ }^{1}\right)$. Über Incubation zum Zweck der Krankenheilungen erfahren wir im Alten Testamente nichts. Damit ist aber nicht bewiesen, daß nicht auch solche geübt wurde. Auch für die Traumorakel sind wir nur auf die Rückschlüsse angewiesen, die sich aus den historischen Erzählungen und der heiligen Sage noch machen lassen. Mit dem geistigen Gottesglauben des nachexilischen Judentums standen aber jene Reste der alten Volksreligion in einem solchen Gegensatz, daß man es für gut befand, diese Spuren, wo es ging, zu verwischen. Wenn sich in dem Orient sonst die Spuren derartiger Heilungsincubationen nachweisen lassen, so werden wir auch wohl ähn. liches von Palästina annehmen dürfen. Und man könnte versucht sein, in der Anwendung des Öles bei der Incubation in Bethel den Rest hiervon zu erblicken. Denn das Öl bildete einen wichtigen Bestandteil bei der Therapie ${ }^{2}$ ).

Für die Verbreitung der Sitte der Incubation in Babylon spricht der oben erwähnte Bericht, wonach sich ein derartiges Orakel des Sarapis in Babylon befand. Daß man dem Ba'al auch, abgesehen von dem aus dem Alten Testament bekannten, die Kraft zuschrieb, durch Orakel Auskünfte zu geben, erhellt aus Dio Cassius LXXVIII, 8, wonach Caracalla von dem Belos (= Ba'al) von Apamea ein Orakel erhielt. Demselben Gott hat im fernen Gallien noch ein Verehrer eine Inschrift gesetzt (CIL XII, Nr. 1277), die lautet: sỏvoveijpt B $r i \lambda \omega$

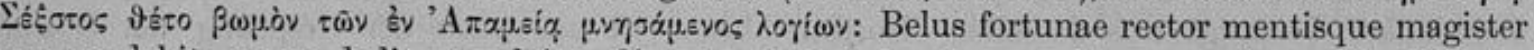
ara gaudebit, quam dedit et volvit. Charakteristisch ist das magister mentis, wofür Hirschfeld (a. a. O. p. 164) vergleicht CIL VI, 499: diis animae suae mentisque custodibus, was nicht genau paßt. Denn dieser Ba'al ist der magister mentis, weil er im Traum dem Incubanten einwohnt und dadurch, daß er seinen Geist beherrscht, ihm Orakel giebt. Daß es sich um Orakel handelt, erfahren wir auch aus der griechischen Fassung. Hierher gehört wohl auch die Inschrift, die von einer Schenkung an den Ba'al des syrischen, in der Nähe von Apamea gelegenen Ortes Baitokaike berichtet (CIG III, Nr. 4475, CIL III, Nr. 184, dazu die Ergänzungen, die Le Bas-Waddington, Voyage archéologique en Asie mineur III, Nr. 2720, p. 630 gegeben hat und die von Mommsen a. a. O. p. $972^{\mathrm{b}}$ verwertet sind). Die Inschrift, die ein Dekret Valerians enthält und die dadurch in die Zeit nach 253 und vor $259 \mathrm{n}$. Chr. versetzt wird ${ }^{3}$, zerfalltt in drei Titel, eine Bestätigung alter Sehenkungen durch Valerian, die Schenkungsurkunde des nicht näher zu bestimmenden Königs Antiochus, und eine Ernenerung dieses Dekretes zugleich mit einer Erweiterung der ursprünglichen Schenkung durch Augustus. Aus der eigentlichen Schenkungsurkunde, bestehend in einem Briefe des Antiochus an einen gewissen Euphemus, lernen wir, daß der König das Dorf Baitokaike, das zur Satrapie Apamea gehörte, samt seinen Gefällen dem Heiligtume des Gottes Zeus (= Ba'al) von Baitokaike $\left.{ }^{4}\right)$ vermachte zu dem Zwecke, daß die Einkünfte für die monatlichen Opfer und für die Vergrößeruug des Heiligtums verwendet werden sollten. Das Dekret befiehlt, daß monatliche Feste

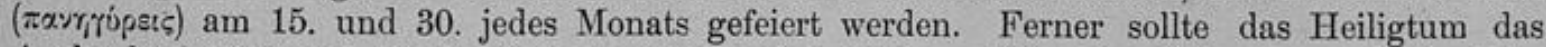
Asylrecht haben und das Dorf einquartierungsfrei bleiben. Wer dem Dekrete zuwiderhandele,

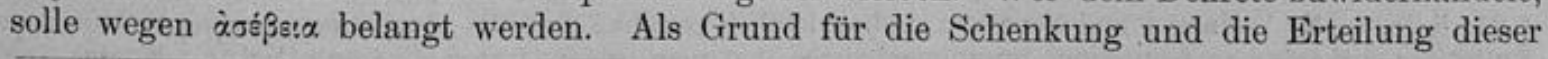

1) Vgl. Stade a. a. O. - 2) Stellen bei Winer, Biblisches Real-Wörterbuch ${ }^{3}$ I (Leipzig 1847), S. 91 f.,

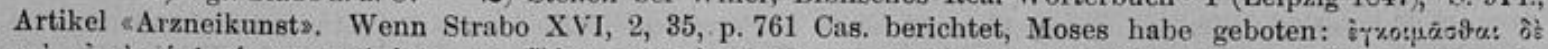

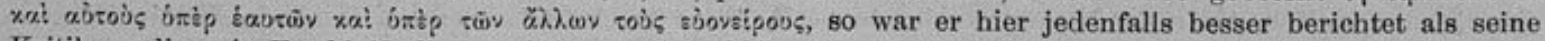
Kritiker, die, wie Ewald (Jüdische Altertümer ${ }^{3}$, S. 344), einen Irrtum annahmen. Noch die LXX wußten von

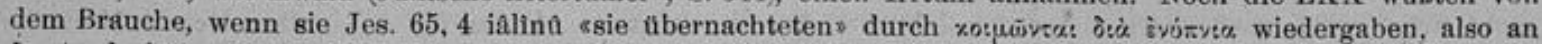
Leute dachten, die an den Gribern sich Orakel holten. - 3) Valerian wurde nach der Ermordung Ämilians im August 203 Kaiser, vgl. Goyau, Chronologie de l'empire Romain, p. 303. - 4) Zu dem Ausdruck vgl.

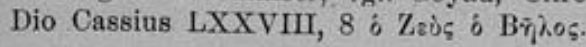


Freiheiten führt der Brief die ṡvśpłsıl des Gottes an. Unter diesen Machterweisen des Báal ist, wenn man den Sprachgebrauch beachtet, wie er uns noch später im Neuen Testament entgegentritt ${ }^{1}$ ), nichts anderes gemeint als die wunderbaren Kuren, die er ausgeübt, und die treffenden Orakel, die er im Traume erteilt hat. Daß als Tage für die Festfeiern gerade der fünfzehnte und der dreißigste jedes Monats genannt werden, findet seine Erklärung in dem Zusammenhang des Kultes mit den lunaren Erscheinungen, die in dem Kulte der chthonischen Gottheiten überhaupt eine große Rolle spielen ${ }^{2}$ ).

Was nun die Vermutung, daß der Kult des Ba'al von Baitokaike mit dem des Sarapis eine gewisse Verwandtschaft zeigt, vortrefflich stützt, ist der Umstand, daß die Urkunde von den xátoyot áyiou ob̉pavion Atós errichtet ist. Also auch hier treffen wir wieder dieselbe Bezeichnung, und auch hier kann es kaum zweifelhaft sein, daß es sich um Hierodulen handelte, die sich in diesem Kulte mit einem der spezifisch orientalischen Begriffssphäre angehörigen Ausdrucke als die "Besessenen * bezeichneten. Diese *ḋo\%ot treten uns noch in einer zweiten, an demselben Orte gefundenen Inschrift ${ }^{3}$ ) entgegen, die uns die aus ihren Mitteln bestrittene Errichtung eines Votivsteines meldet (CIG III, Nr. 4475).

Es ist hier wichtig, festzustellen, weleher Art der Ursprung des Sarapiskultes war. Die Beobachtungen, die wir über sein Vorkommen machen können, weisen uns in den Orient. Die Verwandtschaft mit ausgesprochen orientalischen Lokalkulten, wie dem des Báal von Baitokaike, bestätigt uns dasselbe. Dorthin aber weist uns auch der Ursprung der Götterfigur des Sarapis selbst. Es war lange ein Streit über die Frage, ob Sarapis ein ägyptischer Gott oder ob er eine fremde Göttergestalt sei, die erst später in Ägypten eingeführt wurde. Für die erstere Annahme schien entschieden der Umstand zu sprechen, daß der Sarapiskult in einem noch erkennbaren Zusammenhange steht mit dem Kulte des Osiris-Apis, ja daß der Name 'Orojpartৎ, wie wir ihn gelegentlich in einem Papyrus finden (Lond. XLI [XII], 7), auf ăgyptischen Ursprung schließen läßt. Denn Osar-hapu ist der Osiris-Apis, der als oberster Gott unter die Götter versetzte Apisstier ${ }^{4}$ ). Daß Sarapis entstanden sei aus einer Verbindung von Osiris und Apis, behauptet auch Clemens Alexandrinus, der im Protrepticus $48 \mathrm{sq}$. (p. $42_{19}$ sqq. Potter) sein Wissen über Sarapis ausbreitet und verschiedene Meinungen über seinen Ursprung mitteilt. Bei dem Streite darüber, ob Sarapis eine einheimische oder eine importierte Gottheit sei, hat man früher zu wenig beachtet, daß der Zusammenhang mit dem Osiris- und Apiskulte noch kein ausreichendes Indicium dafür abgiebt, daß der Kult der Gottheit wirklich in Ägypten entstanden sei. Denn wenn Sarapis wirklich ursprünglich eine fremde Gottheit war, so konnte ihr Kult in Ägypten doch nur unter der Voraussetzung eingebürgert werden, daß sie mit den alten Nationalgöttern irgend eine Verbindung einging. Den Späteren konnte das dann leicht als eine natürliche Verwandtschaft erscheinen. Dazu kam auch noch die nationale Eitelkeit der Ägypter, die natürlich ihr Pantheon nicht so leicht einem fremden Gast geöffnet zu haben eingestehen mochten. Die neueren Forschungen haben

1) Vgl. Pbil. 3, 11. Kol, 1, 29; 2, 12. 2. Thess. 2,9-11. Eph. 1, 19; 3, 7. 2. Macc. 3, 29. 3. Mace. 4, 21; 5, 28. - 2) Vollmond und Neumond sind absichtlich gewihlt. Daß die Ineubationen irgendwie mit dem Kulte der chthonischen Gottheiten zusammenhaingen, hat man schon früher erkannt. Vgl. K. Köhler, Der Prophetismus d. Hebräer u. d. Mantik d. Griechen (Darmstadt 1860), S. 26; v. Wilamowitz, Isyllos v. Epidauros, 1886, S. 96. Infolge dieses Zusammenhanges ist es auch verstaindlich, warum Papinius seine Incubation bei

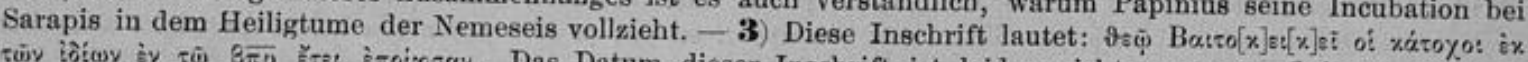

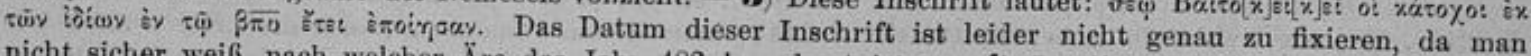
nicht sicher weiß, nach welcher $\ddot{\mathrm{r} a}$ das Jahr 482 berechnet ist. - 4) Da die Apisgräber sich in Memphis befanden, der Sarapistempel in Memphis nach Pausanias (I, 18,4) das ilteste Heiligtum in Ägypten war, so schien auch das diesen Zusammenhang zu beweisen. Über die Entwickelung des Apiskultes s. in Kürze
E. Meyer, Gesch. Ägyptens (Berlin 1887), S. 379 . 
über diesen Punkt eine größere Klarheit gebracht und die von Zoëga, Eckhel, Pléw ${ }^{1}$ ) und anderen vertretene Meinung von dem außerägyptischen Ursprung des Sarapis außer Zweifel gestellt. Nachdem bereits Wilcken im Philologus 53 (N. F. 7), S. 119 Anm., vgl. S. 126, vermutet hatte, daß in dem von den Freunden Alexanders vor dessen Tode befragten Sarapis der Kultbeiname irgend einer babylonischen Gottheit stecken müsse, als den Frz. Delitzsch

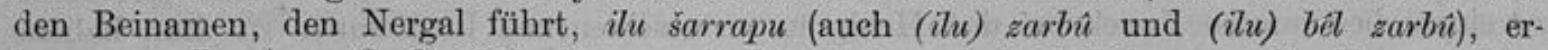
kennen wollte (a. a. O. S. 126), ist von A. Dieterich und C. F. Lehmann die Frage weiter erörtert worden. Der erstere hat in einem Vortrag auf der Dresdener Philologenversammlung eine interessante, religionsgeschichtlich wertvolle Skizze von der Einführung und Verbreitung des Sarapiskultes gegeben ${ }^{2}$ ), der zweite ebenfalls in einem Vortrag namentlich auch die etymologische Frage erörtert ${ }^{3}$ ). Lehmann sucht in Anknüpfung an Wilckens Vermutung den Namen in dem Kultbeinamen eines Heilgottes. Als solchen findet er Ea ( $\mathrm{Ja}$ vgl. hebr. Jahwe), dessen Kultbeiname šar apsî "König des Oceans» gewesen sei. Die verschiedene Aussprache des Beinamens (šar apsi - šar apsi - šar aps - šar apis) habe zu einer Form geführt, die dem Griechen als Sarapis geklungen habe. Ob diese Folgerungen wirklich stichhaltig sind und ob die Ergebnisse von heute denen der Zukunft standhalten werden, vermag ich nicht $\mathrm{zu}$ beurteilen. Das wenigstens ist schwer zu sagen, warum der «Fürst des Oceans s gerade der Heilgott ist, wie der Kultbeiname in Verbindung stehen soll mit der hauptsächlichsten Kulteigenschaft. Aber wie dem auch sein mag, soviel läßt sich jetzt schon sagen, daß das Suchen nach einer orientalischen Etymologie des Namens einen Erfolg verheißt, während die Deutungsversuche aus dem ägyptischen, die Jablonski ${ }^{4}$ ) u. a. angestellt haben, vollkommen fehlgeschlagen sind.

Hiermit stimmt auf das beste die Erzählung von der Einführung des Kultes in Ägypten. Tacitus (histor. IV, 83 sq.), Plutarch (de Iside et Osir. 28), Clemens Alexandrinus (Protrept. 48 sq.) und Cyrillus Alexandrinus (Contr. Jul. I, t. VI, 2 p. 13 D Aubert.) berichten übereinstimmend, daß Ptolemäus das Götterbild des Sarapis aus Sinope geholt habe. Nach Tacitus soll es ein Bild des Jupiter gewesen sein; die andern nennen Pluto. In der That wird es irgend eine Ba'alstatue gewesen sein. $\mathrm{Da}$ es eine chthonische Gottheit gewesen sein müsse, konnte man aus der Thatsache schließen, daß Incubation bei ihr stattfand. Daher der Vergleich mit Pluto. So haben wir denn im Sarapiskulte auch nicht irgend eine ägyptische Institution zu erblicken und demnach auch kein Recht, andere Maßstäbe anzulegen als die, die uns aus den orientalischen Kulten bekannt sind. Die « $\dot{\tau} \tau$ \%ot sind demnach weiter nichts, als die von der Gottheit ergriffenen Incubanten, die bei dem Ba'al Sarapis ein Orakel suchten oder von ihm Heilung begehrten.

Es lag in der Natur der Sache, daß auch in Griechenland zu einer Zeit, in der die Kulte der chthonischen Gottheiten ganz allgemein in Aufnahme kamen und besonders der des Asklepios wuchs, nämlich eben in der hellenistischen ${ }^{5}$ ), der des Sarapis an Verbreitung gewann. Der Rhetor Aristides zählte dreiundvierzig Heiligtümer des Gottes und weiß seine Kunst nicht hoch genug zu preisen. Incubation war etwas sehr häufiges und die Inschriften,

1) Zoëga, Numi Aegyptii imperii prostantes in Museo Borgiano Veletris (Romae 1787), p. 78; vgl. Bibliothek d. alten Litteratur u. Kunst, St. 7 (Gött. 1789), S. 58 ff.; Eekhel, Doctrina nummorum IV, p. 29 sqq.; E. Plew, De Sarapide 1868 (Diss.). - 2) Vgl. Verhandlungen der 44. Versammlung deutscher Philologen u. Schulmänner in Dresden 1897 (Leipzig 1897), S. 31 ff. - 3) Der Bericht über den Vortrag im Nov. 1897 in der Berliner archäolog. Versammlung steht in der Berliner philolog. Wochenschrift 1898, Nr. 4, Sp. 123 ff. Vgl. auch Zeitschr. f. Assyriol. 12 (1897), S. 112. - 4) P. E. Jablonski, Pantheon Aegyptiorum II, p. 255 sqq. Er meint, es sei ursprünglich der Nilpegel gewesen dschêr-êpi. Zoëga meinte, dem Wesen des Gottes viel besser entsprechend, es sei in Sarapis adschörapis = Herr der Finsternis, d. h. König des Todes verborgen. - 5) Zur Verbreitung dieser Kulte in der hellenistischen Zeit, besonders des Asklepioskultes, vgl. Stark, Über die Epochen der griechischen Religionsgeschichte, Verhandlungen d. 20. Versammlung deutscher Philologen u. Schulmänner zu Frankfurt a. M. (Leipzig 1861), S. $71 \mathrm{ff}:$ 
die dankbare Patienten setzen ließen, wenn der Gott sie von Indigestionen, Kopfweh und andern Übeln befreit hatte, lassen uns interessante Einblicke in die religiöse Medizin der Zeit thun, wie der amüsante Krankenbericht, den M. Julius Apellas in Epidauros im Steine verewigen lie $\beta^{1}$ ). Bemerkenswert ist aber dies, daß wir es bei den Sarapisheiligtümern und nicht anders bei den als Heilgottheiten verehrten orientalischen Ba'alim nicht nur mit einzelnen, zu einem bestimmten Zweck bei den Heiligtümeen erschienenen Incubanten $\mathrm{zu}$ thun haben, sondern auch mit einer Gilde von solchen, die mit dem Heiligtume in einer gewissen Verbindung standen und offenbar für Geld andern dazu behülflich waren, ein Orakel oder Auskunft über irgend welche in einem besonderen Falle anzuwendenden Medikamente zu erhalten. Für das große Sarapeum bei Memphis ergiebt sich das aus den Papyri. Ptolemäus, wie auch sein Bruder Apollonius bezeichnet sich in dem Eingang seiner Bittgesuche als *zur Gilde der

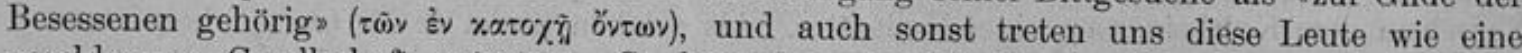
geschlossene Gesellschaft entgegen. So besonders deutlich in der Eingabe an den König über die unerlaubte nächtliche Durchsuchung der Wohnung und das Eindringen der Priester und Polizeibeamten in das Heiligtum. Ebenso lassen sich die "Besessenen" des Báal von Baitokaike als Gilde erkennen, wenn sie ein Dekret in Stein errichten oder eine Votivsäule weihen. Die Motive, die den einzelnen zum Eintritt in die Gilde bewogen, mögen recht verschieden gewesen sein. Bei Ptolemäus, dem Sohn des Glaucias, war es ein Rückgang seiner Vermögensverhältnisse, der eine Folge der Bürgerkriege war, denen sein Vater zum Opfer fiel. Bei andern waren es wohl ähnliche Motive, wie sie die zabllosen Scharen von Tempelbeamten, die jedes größere Heiligtum aufwies, zu ihrem Dienste veranlaßt hatten: die Aussicht auf ein zwar nicht glänzendes, aber immerhin sorgenfreies Leben. Denn daß sie ein solches zu erwarten hatten, trotz dem Bettler Harmais (Pap. Lond. XXIV [XV]), läßt sich wohl kaum bezweifeln ${ }^{2}$ ). Noch nie haben die, die auf den menschlichen Aberglauben spekulierten, in der Welt ein schlechtes Geschäft gemacht. Und die beweglichen Klagen des Ptolemäus in seinen Bettelbriefen, die Bitten, ihn durch Erfüllung seiner Wünsche vor dem Verhungern zu schützen, sind sicher nicht so tragisch zu nehmen.

Über die eigentliche Thätigkeit dieser Gilde, über die wir in den Bittgesuchen und Herzensergüssen nichts erfahren, geben uns einige Papyri höchst wertvolle Aufschlüsse. Es sind diejenigen Urkunden, in denen sie ihre Träume aufzeichneten ${ }^{3}$ ). Leider sind es nur dürftige Trümmer einer jedenfalls nicht unbeträchtlichen Litteratur, die uns ein glücklicher Zufall geschenkt hat. Aber sie reichen doch aus, um uns in die Werkstätte jener Träume in den Heiligtümern zu versetzen. Daher verlohnt es sich, etwas näher darauf einzugehen. Das erste Schriftstück (Par. 50) stammt aus dem Jahre 160 v. Chr. und erzählt von Träumen, die ein gewisser Nechthonbes ${ }^{4}$ ) im Monat Pharmuthi gehabt hat. Der Anfang ist für mich nicht übersetzbar, weil Worte aus einer anderen Sprache eingemischt sind. Dann heißt es: «Zum dritten sah ich den Ptolemäus, der mit einem Schwerte in der Hand durch das Quartier eilte und an die Thüre klopfte; und sie wird geöffnet... indem er ihn schlagen wollte. Ich sage: das darfst du nicht thun, sonst wirst du dein Kind verlieren ${ }^{5}$ ). Der Herr (d. h. Sarapis = ba al!) löst nicht $\left.\operatorname{sein}^{6}\right)$ Kind. - Ein Weib sitzt auf einer Matratze, hat ein Kind auf der Matratze.

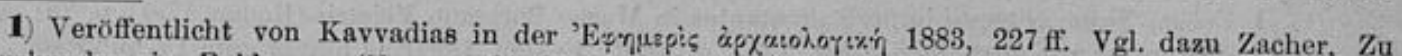
den Heilurkunden in Epidauros (Hermes 21 [Berlin 1886], S. $467 \mathrm{ff}$ ); v. Wilamowits, Isyllos v. Epidauros (Philolog. Untersuchungen, Heft 9, 1886), S. $116 \mathrm{ff}$ - - 2) Hierüber geben uns die Tempelrechnungen, die uns ans dem Sarapeum von Memphis erhalten sind, sehr dankenswerte Aufschlüsse. Man vgl. das Verzeichnis der Bareinnahmen des Apollonius in Par. 57. - 3) Strabo berichtet XVI, 1, 17, wie oben erwahnt, von der Sitte, daß die Incubanten ihre Träume aufzeichneten. - 4) Der Name ist wohl mit dem Par. 35, 13. 37, 34

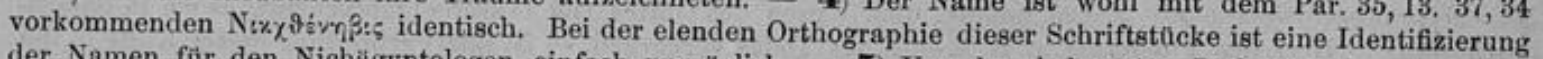
der Namen für den Nichägyptologen einfach unmogglich. - - 5) Um den bekannten Ptolemäus kann es sich nicht handeln. Denn der behauptet, keine Kinder zu haben (Lond, XXIII [II], 9). Der Papyrus stammt aus dem J. 158, - 6) Der Pap. hat à̉̇oō; gemeint ist coó oder der Satz stellt die Deutung des Traumes dar: das Kind
wird nicht gesund werden. 
Ein anderes Weib ihr gegenüber auf einer andern Matratze. Sage ich zu ihr: deine Matratze besteht aus Gemüsepflanzen und Kohl; sie sitzt und bewegt sich nicht.» Bei dem ersten dieser Traumgesichte können wir noch die Beziehungen ahnen. Ein Mann Namens Ptolemäus verlangt ein Orakel wegen seines kranken Kindes. Ob es der Gott von seiner Krankheit lösen wird oder nicht, will er durch die Incubation der "Besessenen s erfahren.

Ein anderer Traum, der auf demselben Papyrus steht und von demselben Nechthonbes herrührt und der sich, wie ausdrücklich gesagt wird, s von der Besessenheit der Zwillinge und von mir, der ich im Unglück bin und vom Hause», handelt ${ }^{1}$ ). eIch träumte, jemand spräche zu mir: Gieb mir die Haut deines Fußes, und ich gebe dir die Haut meines Fußes. Ich sage: Ich will nicht. - Zu zweit: Ich träumte, das Haus werde abgerissen, . . indem (er) es schöner machte ${ }^{2}$ ). - Zu dritt: Ich träumte, ich hätte eine Taube. Sie fliegt mir aber aus der Hand, und ich laufe hinter ihr drein mit den Worten: Ich will sie nicht entwischen lassen. Ich greife sie wieder und nehme sie in meine linke Hand, und (halte sie fest), damit sie nicht wieder fortfliegt ${ }^{3}$ ). - Zu viert: Ich träumte, zwei Frauen säßen mit einem Manne zusammen. Sie thun ihm schön und schwören so zu der heiligen Isis.s Es ist offenbar, daß diese kurzen Notizen nur den Anhalt bieten sollen für die Auslegung, die den berufsmäßigen Traum-

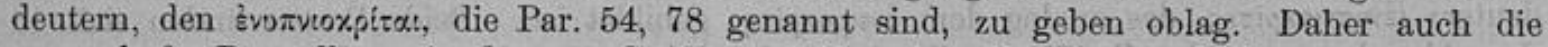
sprunghafte Darstellung, in der nur die Traumbilder eben. Erwähnung finden.

In dem Pap. Par. 51 erhalten wir einen etwas ausführlicheren Bericht von einem Traum, den Ptolemäus selbst in der Nacht vom 12. zum 13. Tybi des Jahres 160 hatte. EIch träumte, ich ginge von Süden nach Osten und fiele auf eine Spreu. Und südlich von mir war jemand, der sich an mir hielte. Auch er fällt hin, und meine Augen waren wie geschlossen. Plötzlich öffne ich meine Augen und sehe die Zwillinge in der Schule des Tothes. Sie riefen, ich antwortete....4), denn ich habe mein Lager gewechselt. Ich hörte Tothes, der sprach: Ich bete. Was sagst du da? Ich habe dir die Zwillinge anvertraut und ich sehe, daß du sie prostituierst. Ich weine vor ihnen. Ich gehe hin, bis ich sie erfasse, und komme mit ihnen in das Quartier. lch sagte zu ihnen: Ich habe noch kurze Zeit in dem Tempel (?) zu thun, und es wird früh sein, wie vorher. Ich sah eine von ihnen an einen dunkeln Platz gehen und sich ausspähend niedersetzen. Ich sah . . sich niedersetzen. Ich sage zu Harmais, er solle schnell herankommen und noch anderes. Ich sah vieles und bat Sarapis und Isis: Komme zu mir, Göttin der Götter, sei gnädig, erhöre mich; habe Mitleid mit den Zwillingen. Du hast die Zwillinge dazu verdammt. Mich hast du mit meinen grauen Haaren erlöst; aber sieh, bald werde ich Ruhe haben. Sie aber sind Weiber. Wenn sie nicht blühen, so werden sie nie rein.s Von dem folgenden Traum ist nur der Anfang noch übersetzbar, der Schluß so stark zerstört, daß man keinen Zusammenhang mehr in die Reste bringen kann. Der Anfang lautet: aIch träumte, ich wäre in Alexandria auf einem großen Turme. Ich hatte ein schönes Gesicht. Ich wußte es, ich wollte aber mein Gesicht nicht zeigen, weil es schön war. Eine alte Frau saß bei mir und eine Menge nördlich und südwestlich von $\operatorname{mir}^{5}$ ).... Aus dem ersten Traum müßten wir über die Stellung der beiden Priesterinnen Schlüsse ziehen, die damit stimmten, daß im Sarapeum auch Astartedienst getrieben wurde, wenn es nicht eben ein Traum wäre. Es geht also nicht an, aus diesen Traumbildern mehr zu entnehmen, als wir aus den andern Quellen belegen könnten. Daß man mit Schlüssen sehr vorsichtig sein muß, beweist auch das, was Ptolemäus hier von

1) Das kann sich auf die oben erwähnte Angelegenheit wegen des viterlichen Hauses beziehen,

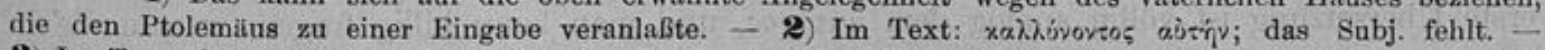
3 Im Text: $\beta \dot{\alpha} s t \omega$, was ich nicht verstehe. Der Sinn ist wohl der der eingeklammerten Worte. - 4 Die

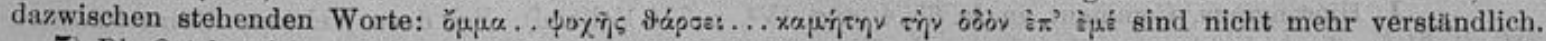
-5) Die Ortsbezeichnungen werden von Ptolemäus stets so gewissenhaft angegeben, daß man darauf schließen muß, es sei gerade anf sie bei der Deutung besonders viel angekommen. 


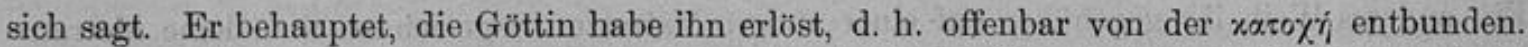
Das entspricht jedoch nicht den Thatsachen, da wir ihn in den späteren Urkunden noch in derselben Situation antreffen.

Mehrere Träume derselben Personen finden sich auf der Rückseite des Leydener Papyrus C. Da sie aber kein besonderes Interesse mehr bieten und da Leemans in seiner Ausgabe (Papyri Graeci Musei antiquarii Lugduni-Batavi I, p. 117 sqq.) zugleich eine Übersetzung geliefert hat, so kann hier von einem genauern Eingehen auf sie abgesehen werden.

Endlich wäre aus den Rechnungen über die Lieferungen an die Zwillinge, Ptolemäus Apollonius und andere Bewohner des Sarapeums noch mancherlei über die Zustände zu ent. nehmen; doch das müßte in anderem Zusammenhange durchgeführt werden, und dazu fehlt hier der Anlaß. Erwähnung verdient aus diesen interessanten Dokumenten ein Posten über Lieferung eines b̧óv:ov È rrout.jto:y (so geschrieben!), d. h. irgend eines Linnenstückes, das bei

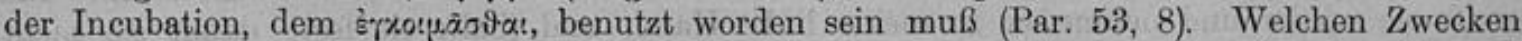
es dabei gedient hat, ist nicht deutlich. Sonst benutzte man als Unterlage für den Tempelschlaf das Fell eines vorher geopferten Widders, welche Sitte noch Hieronymus bezeugt ${ }^{1}$ ). Ferner in einer andern Abrechnung (Par. 54, 78) die Ablieferung von Linnen an den sTraum-

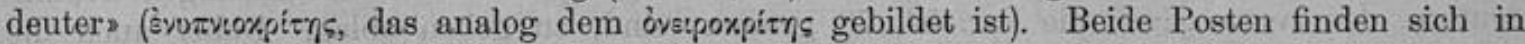
den Abrechnungen der Zwillinge, die demnach mit der Incubation ebenfalls irgendwie zu thun hatten. Da auch von ihnen Träume überliefert sind, ist diese Stellung, die sie im Tempelorganismus zu irgend einer Zeit einnahmen, jedenfalls nicht zu bezweifeln. Daß sie daneben noch priesterliche Funktionen ausüben, beweist hiergegen nichts.

Es wird nun noch darauf ankommen, für das oben ermittelte Institut der Gilde von professionsmäßigen Incubanten eine Parallele in den orientalischen Religionen $\mathrm{zu}$ finden. Denn da, wie oben gezeigt wurde, der Name der xároyot mit der ihm zu Grunde liegenden Vorstellung des Besessenseins von dem Geiste der Gottheit uns in den Orient weist, da ferner in einem spezifisch orientalischen Kulte Sache und Namen uns wieder begegnen, so werden wir auch für die eBesessenen» des Sarapis einen orientalischen Ursprung anzunehmen haben. Damit das Gebiet, auf dem die Parallele zu suchen ist, richtig bezeichnet ist, wird es passend sein, von einer Beobachtung auszugehen, der an und für sich nicht allzuviel Beweiskraft innewohnt, die aber in diesem Zusammenhange doch nicht unbrauchbar ist. Eine alte Glosse stellt das lateinische Äquivalent von xároxos, nämlich fanaticus, zusammen mit ípartxós ispóóou $\left.\rangle_{0}{ }^{2}\right)$. Der Boden, auf dem wir also den Ursprung des in Frage stehenden Begriffes zu suchen haben, ist das Gebiet der Hierodulie. In ihr haben wir eine völlig analoge Erscheinung, und ihre Bezeichnung auf dem semitischen Sprachboden entspricht der, die wir auf dem griechischen Boden finden, durchaus.

Die Propheten, unter die Saul geriet und deren Begeisterung sich wie bei Korybanten u. a. in wilden Tänzen verriet, heißen im Hebräischen mésugg 'im; das Wort ist das Passivpartizip einer Intensivkonjugation von einem Verbum śâga, das eigentlich eine stammelnde,

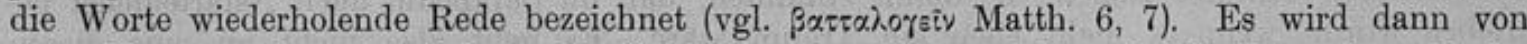
jeder Ekstase gebraucht, bei der das Subjekt seiner Sinne nicht mächtig ist, wie auch im Arabischen das Verbum rasende Tiere, wie z. B. scheugewordene Kamele, bezeichnet. Die LXX übersetzen es - nicht genau - mit छ̇i

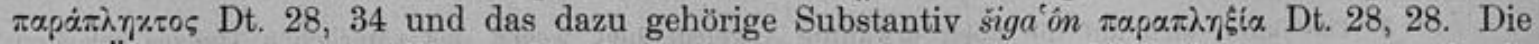
erste Übersetzung ist völlig analog dem «áro $\varsigma^{\circ}$, und man kann billig fragen, warum die in

1) Hieronymus, Comment. in Is. 65,4 (opp. IV , p. 774 Vallarsi). Vgl. dazu Welcker, Kleine Schriften III, S. $91 \mathrm{f}$. Auch in der unartigen, aber lustigen Schilderung, die Aristophanes Plutus $653 \mathrm{ff}$. gegeben hat, ist die Sitte erwahnt. - 2) Corpus Glossarum Latinarum edd. Goetz et Gundermann II (Lipsiae 1888), p. 70, 31. 
Ägypten lebenden Übersetzer des Alten Testamentes statt eines durchaus gebräuchlichen und zutreffenden griechischen Ausdrucks einen andern gewählt haben, der zwar dieselben Gedanken ausdrückt, aber doch in dem Griechischen nur von Erscheinungen gebraucht wird, die in das psychopathische Gebiet fallen ${ }^{1}$ ). Von der Begeisterung eines Propheten oder Korybanten wird es aber nicht angewandt. Den Grund für dieses Umgehen des Begriffes kann man noch ahnen. Waren die жdro 0 ot die Besessenen des Sarapis, so durfte man mit ihnen nicht die Jahwepropheten auf eine Stufe stellen ${ }^{2}$ ). Daher vermied man lieber diesen anstößigen Titel und wählte einen solchen, der zwar ungebräuchlich war, aber immerhin das Wesentliche der Sache doch zum Ausdruck brachte. Religionsgeschichtlich wichtig ist in dieser Hinsicht eben dies, daß die zu Grunde liegende Vorstellung hier wie dort dieselbe war. Bei den Jahwepropheten wirkt der göttliche Geist eine sich in wilden Tänzen äußernde, wohl auch die Sprachorgane beeinflussende Begeisterung: die "Besessenen" des Sarapis sehen Visionen, empfangen Orakel und werden durch den göttlichen Geist geheilt. Die Äußerungen sind verschieden; das Wesen der Sache bleibt dasselbe.

Dennoch liegt kein rechter Anlaß vor, in den "Besessenen» eine Art von Sarapis. propheten zu erblicken, wenn sich dafür auch manches anführen ließe. Die Propheten der älteren Zeit, die vor dem Exile und wahrscheinlich viel länger existiert haben, als das unsere Quellen ausdrücklich verraten, waren, wie uns das Auftreten Sauls unter ihnen lehrt, auch in Schwärmen organisiert, die man als Gilden fassen könnte. Freilich durften sie sich frei bewegen, während die Besessenen an das Heiligtum gebunden blieben. Aber wer bürgt uns, daß nicht auch an den Jahweheiligtümern, wie in Bethel, solche Propheten die Incubation vorzubereiten hatten? Aber, wie bereits bemerkt, auf solehe Parallelen ist nicht viel zu geben. Bestimmte Beweise lassen sich hier nicht führen.

Dagegen ist auf ein anderes, an den orientalischen Heiligtümern übliches Institut, das offenbar einer festeren Organisation nicht entbehrte, hinzuweisen, mit dem das beim Sarapiskult nachweisbare im Namen eine erkennbare Verwandtschaft besitzt. In den orientalischen Kulten war eine Form der Hierodulie verbreitet, die nur unter der Voraussetzung verständlich ist, daß die Gottheit an die ihr geweihten Personen nicht nur mit ihrer Seele, sondern ebenso auch mit ihrem Leibe Anspruch machen darf. Von der bei den Babyloniern verbreiteten Sitte der Hingabe des eigenen Leibes im Dienste der Gottheit hat bereits Herodot gewußt und er hat sie beschrieben $(I, 199)$. Dort handelt es sich nicht um eine feste Organisation, sondern um eine Sitte, die von jedermann geübt wurde. Daß aber eine solche Organisation im Orient thatsächlich bestand, wissen wir aus andern Zeugnissen. Von den Hierodulen in Comana in Pontus berichtet Strabo (XII, 3, 37), und wegen dieser Verhältnisse nennt er die Stadt ein «Klein-Korinth». Hier tritt uns die Sache selbst, die Organisation der Hierodulen, entgegen und auch der Name. Strabo bezeichnet die dort im Kulte beschäftigten Frauen ausdrücklich als ispai, d. h. als der Gottheit geweiht.

Die Sitte war, wie es scheint, im ganzen Orient verbreitet und auch Israel nicht fremd. Dort führen diese Hierodulen den Namen qedéšim. Das Wort kommt von dem Verbum qádás, das in quadôs «heilig», d. h. der Gottheit geweiht, vorliegt, ebenso in qodes «Heiligtum». Seiner Bildung nach bezeichnet qâadéš, von dem qedésî̀ der Plural ist, einen dauernden Zu-

1 Die Geisteskrankheiten, Epilepsie u. s. w. werden allerdings im Orient und auch sonst dem Einwohnen von Damonen zugeschrieben (s. den Artikel «Damonische» von J. Weiß in Hauck, Real-Encyklopädie für prot. Theol. u. Kirche ${ }^{3}$ IV, $410 \mathrm{ff}$.). Aber man hat die Propheten nie mit Epileptikern auf eine Linie gestellt, weil eben der in ihnen wirkende Geist ein anderer war als der, der Epilepsie hervorrief. Für uns liegt die Parallele

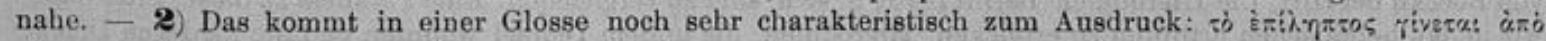

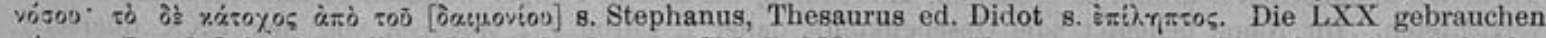
xároyos Jon. 2, 7 in demselben Sinne, in dem es CIG I, $538 \mathrm{sq.} \mathrm{von} \mathrm{Hermes} \mathrm{und} \mathrm{der} \mathrm{Ge} \mathrm{gebraucht} \mathrm{wird,} \mathrm{also}$

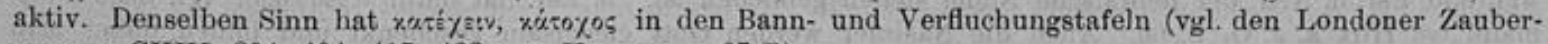
papyrus CXXI, $394,404,417,422$ u. 8 . Kenyon, p. $97 \mathrm{ff}$.). 
stand oder eine dauernde Beschäftigung ${ }^{1}$ ), also hier den berufsmäßig Gottgeweihten. Es sind nicht die Priester darunter verstanden - für sie giebt es nur die Bezeichnung lồhên, was ursprünglich den Wahrsager bedeutet, wie das arabische kâhhin, vgl. $\mu d \dot{v} v ı \varsigma$ —, sondern die Leute, Männer und Frauen, die ibren Leib selbst der Gottheit opferten und deren Lohn dem Heiligtume zufloß (vgl. Gen. 38, $21 \mathrm{f}$. $)^{2}$ ). Wie die Hierodulen des Sarapis wohnen sie in dem Tempel; erst Josia läßt ihre Wohnung abbrechen. Wie die «Zwillinge» im Sarapeum sind sie mit Leineweberei für das Heiligtum beschäftigt. Wie diese nehmen sie auch an dem Kulte teil (Hos. 4, 14). Die Berührungen sind so zahlreich, daß man wohl nicht fehlgehen wird, wenn man mit dieser Sitte die Gilde der Sarapishierodulen in Verbindung setzt und in ihrem Vorhandensein einen neuen Beweis für den orientalischen Ursprung dieses Kultes erblickt, womit natürlich nicht gesagt sein soll, daß aus der Verwandtschaft der Begriffe auch die Verwandtschaft der Thätigkeit folge.

Dagegen ist wohl nicht hierherzuziehen der Brauch, durch den wir aus einer größeren Anzahl von Inschriften Kunde haben, Sklaven unter der Form der Hierodulie freizulassen ${ }^{3}$ ). Es war das ein Scheinact, der vor dem Priesterkollegium ( CIG Sept I, 3304) vorgenommen wurde, und der dem betreffenden Sklaven unter bestimmten Klauseln in der Weise die Freiheit gewährte, daß er in ein Eigentumsverhältnis zu der Gottheit trat, in deren Heiligtum der Act vorgenommen wurde. Gottheiten, bei denen solche Freilassungen erfolgten, waren außer Sarapis und Asklepios, Apollo, Dionysos, Athena und die Aphrodite Syria ${ }^{4}$ ). Da durch diese Form aber kein dauerndes Verhältnis zur Gottheit begründet wurde, so ist diese Sitte für die Erklärung der $x \alpha \tau \circ \chi \dot{\eta}$ nicht weiter verwertbar.

Dagegen könnte man etwas anderes hier herbeizuziehen geneigt sein. Es fällt auf, daß uns an all den zahlreichen Heiligtümern, die Sarapis in der Kaiserzeit besaß, nirgends eine Spur jener Organisation begegnet, mit Ausnahme von Smyrna und einem kleinen orientalischen Heiligtum, dessen $\mathrm{Ba}$ al wir vielleicht mit Sarapis gleichsetzen dürfen. Die oben besprochenen Inschriften von Baitokaike und die aus Smyrna beweisen uns, daß der Begriff so wenig verloren gegangen ist wie das Wort. $\mathrm{Da} \beta$ man die Sarapisheiligtümer eifrig besuchte und dort durch Incubation Heilung zu erlangen hoffte, wissen wir ebenfalls. Sollte sich dabei eine Gilde in der Blütezeit des religiösen Vereinswesens verloren haben, die doch so sehr den Bedürfnissen des Publikums entgegen kam? Das ist nicht wahrscheinlich. Wahrscheinlicher ist, daß man den fremdartigen Begriff, der sich mit dem Worte xdiroyos verband und der nach abendländischem Empfinden sich mit der Sache so wenig deckte, fallen ließ, die Sache dagegen beibehielt, wenn auch unter anderem Namen.

Nun begegnet uns in den zahlreichen Inschriften, die von dem Sarapiskult im Abendlande Kunde geben, sehr häufig die Bezeichnung vswæópos, und daß wir es dabei mit einer Organisation zu thun haben, zeigt der Titel àpłŁaxópos, der in einer Inschrift - allerdings einer syrischen - uns begegnet (CIG III, 4470). Die xd.royo: des Sarapeums in Memphis und der orientalischen Heiligtümer mit den vswrópo: der abendländischen zu iden-

1) Vgl. zu der Bildung dieser Nomina qațil: Stade, Lehrbuch der hebr. Grammatik I (Leipzig 1879), \$ 202 a, S. $148 \mathrm{f}$. - 2) Vgl. zu der Sitte Movers, Die Phönizier I (Bonn 1841), S. $679 \mathrm{ff}$, wo viel Material zusammengetragen ist. Über den Ursprung der Sitte vgl. Stadé, Gesch. d. Volkes Israel I (Berlin 1887), S. $479 \mathrm{f}$ - - 3) Über die Inschriften, soweit sie damals bekannt waren, hat L. Preller, Bericht über die Verhandlungen d. k. sächs. Gesellsch. d. Wissensch. zu Leipzig, phil.hist. Klasse 6 (1857), S. 195 ff. gehandelt. Jetzt stehen sie bequem zusammen in CIG Sept I, 3301 sqq. - 4) Vgl. darüber Curtius, Anecdota Delphica (Berol. 1843, p. 10 sqq. und in den Nachrichten d. Gött. Gesellsch. d. Wissensch. 1864, Nr. 8, S. 135 ff. Auch die Bemerkungen von Boeckh bei Hirt, Die Hierodulen (Berlin 1818), S. $48 \mathrm{ff}$. sind zu vergleichen. Eine Parallele zu dieser Sitte haben wir in den hebräischen nethinim zu erblicken, Hierodulen, die in dem Tempel wohnten und die niederen Dienste

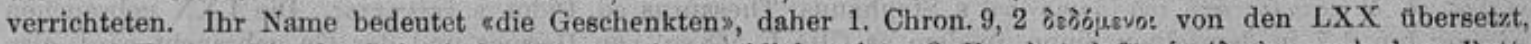
wahrend Esr. u. Neh. der hebräische Name stehen geblieben ist. 3. Esr. hat dafür ́̇póôobخot, vgl. dazu Buttmann bei Hirt a. a. O. S. 66 . Auch die Nasiriler werden Gott gleichsam geschenkt und bilden daher sein Eigentum. A uf diese Zusammenhinge ist hier nicht weiter einzugehen, so interessant und förderlich es auch wäre. 
tifizieren, kann man versucht-sein durch die Inschrift aus Rom, in der Statius Quadratus

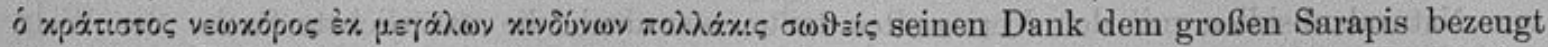
(CIG Sic et Jt 1030). Aus großen Gefahren fand auch der oben (S. 9 ff.) erwähnte Hephästion seine Rettung dadurch, daß er ein xd́royos des Sarapis wurde. Rufin berichtet jedoch (hist. eccl. II, 23), daß bei der Zerstörung des großen Sarapeums in Alexandria aufgefunden wurden die sexedrae et pastophoria domusque in excelsum porrectae, in quibus vel aeditui (d. h. die

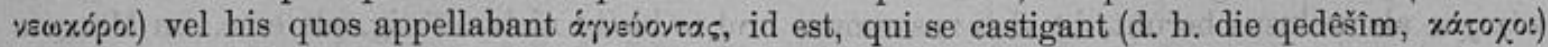
commanere soliti erant». Damit ist deutlich das Nebeneinanderbestehen beider Organisationen wenigstens für den Tempel in Alexandria bewiesen ${ }^{1}$ ). Doch könnten bei anderen Heiligtümern immerhin Verschmelzungen eingetreten sein, die für uns jetzt nicht mehr nachweisbar sind.

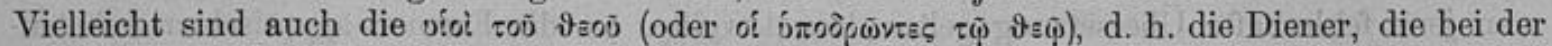
Incubation die Handreichungen zu leisten hatten, mit den жd́royot zu identifizieren ${ }^{2}$ ).

Aus den Erörterungen ergiebt sich also folgendes als Resultat: Die xáro\%ot waren zunächst nur die Personen, die das Heiligtum zum Zwecke der Incubation, um ein Orakel $\mathrm{zu}$ erlangen oder um Heilung zu finden, besuchten. Das Wort bedeutet den von der Gottheit erfaßten, den Besessenen. Diese Besessenheit dauerte, solange er seinen Zweck nicht erreicht hatte ${ }^{3}$ ). Durch die Erfüllung des Wunsches, der den Betreffenden zum Heiligtume getrieben hatte, löste der Gott selber das mit jenem Ausdruck bezeichnete Verhältnis. Daneben gab es noch eine andere Form, die man mit demselben Namen belegte, obgleich der Name Hierodule entsprechender wäre. An den Heiligtümern in Memphis sowie im Orient fanden sich Leute bereit, als Orakelsucher sich für längere Zeit in das Verhältnis zur Gottheit zu begeben. Da es dem allgemeinen Brauch entsprach, nicht nur persönlich die Gottheit zu befragen, sondern dies auch durch andere thun zu lassen, konnte die Entstehung einer solchen Hierodulengilde der Besessenen leicht entstehen.

Der Besessene war an das Heiligtum gebunden, hatte dort seine Wohnung, bezog gewisse Einkünfte und genoß infolge seiner Stellung, trotz des oft bettelhaften Lebens, ein gewisses Ansehen. Inwieweit er in seinem direkten Verkehr mit Privatpersonen beschränkt war, ob die Beschränkung allgemein war oder sich nur auf bestimmte Personen bezog, läßt sich nicht mehr sicher ausmachen. Jedenfalls hängen sie mit dem Umstand zusammen, daß man ihn von der Gottheit selbst unmittelbar berührt ansah.

Diese Ergebnisse berechtigen uns, nun noch kurz auf die Frage einzugehen, welcher Zusammenhang zwischen dieser Gilde und dem christlichen Mönchtum bestanden habe. Für Weingarten war es eine ausgemachte Sache, daß sie «Büßer» waren, die in «unverbrüchlicher Klausur» lebten, ihre Habe daheim ließen, sum von dem Brot zu leben, das ihre Verwandten ihnen brachtens, « unter denen man von Vätern und Brüdern im geistlichen Sinne sprach ${ }^{4}$ ). An diesem Gemälde ist auch nicht ein Strich richtig. Nicht um zu büßen, kamen die angeblichen Mönche in das Heiligtum, sondern um die Hülfe der sgroßen Gottheit» zu suchen, um Orakel zu holen oder sich heilen zu lassen oder auch - um dort einen Beruf zu finden. Nicht in einer Klausur lebte man, sondern in dem Tempelbezirk, den man nicht verlassen durfte, weil ja dort die Gottheit wohnte, deren Eigentum man war, solange der Zustand dauerte. Die Habe verließ man, weil man freilich Immobilien nicht wegschaffen konnte -

1) Bezeichnend ist aus dem Berichte, den Sozomenus, hist. eccl. VII, 15 über die Zerstörung des alexandrinischen Sarapeums giebt, die Episode, in der ein Philosoph Namens Olympius die in dem Tempel

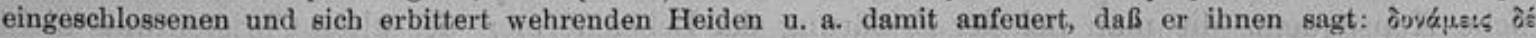

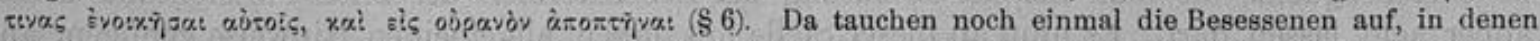
göttliche Krafte wirken. Aber eine andere Gottbegeisterung, die ther den letzten Resten des Heidentums die Brandfackel schwang, war aufgekommen: der wilde Mut der Mönchsscharen aus den nitrischen Bergen. 2) S. über sie Zacher im Hermes XXI (1886), S. 470 f. - 3) Das konnte unter Umstanden recht lange dauern. Aristides hat sich 13 Jahre lang an den verschiedenen Heiligtümern herumgetrieben als cewiger Incubant s. 4) Weingarten, Art. «Mönchtum» in Herzog.Plitt, Real-Encyklop.² 10, S. 781. 
und daß man von ihnen, wie das auch die ägyptischen Priester thaten, den Ertrag in Gestalt von Naturalsubsidien mit den Verwandten teilte, war doch die natürlichste Sache der Welt. Und daß gar der jüngere Bruder den älteren, das Familienoberhaupt, der sich noch dazu in einer so ansehnlichen Stellung befand, mit «Vater» anredet, ist doch kaum eine Sache, die nur bei einer Art von Mönchtum möglich wäre $\left.{ }^{1}\right)$. So stürzt das ganze künstliche Gebäude, das Weingarten aufgeführt hat und das im Grunde allein auf der verkehrten Übersetzung von xd́royos als reclusus beruht, in sich zusammen und es bleibt nichts übrig, als eine, im Morgenland verbreitete und auch im Abendland nicht unbekannte Form der Gottesverehrung.

Damit ist denn auch das Urteil über die Meinung gefällt, als habe sich das älteste Mönchtum aus dieser Büßerkaste von Sarapisdienern entwickelt. Nichts erinnert, selbst wenn man jene fehlerhafte Übersetzung gelten lassen wollte, an die Formen ägyptischen Asketenlebens, wie sie uns aus den ältesten Mönchsgeschichten bekannt sind. Da treten uns in den Führern, aber auch in den Geführten Menschen entgegen, die mit einer grausamen Wollust jede Spur des Empfindens ertöten, die jeden Rest eines sich selbständig regenden Willens ersticken, damit ja die Seele durch das elende Gehäuse des Körpers, in den sie gebannt ist, keinen Schaden leide. Die in die Wüste fliehen, auf steilen Felsen sich einnisten, damit sie nur nicht durch den Gedanken an die Möglichkeit einer Hülfe seitens der Brüder einmal schwach werden. Die keine andere Speise kennen als die harte Brotrinde, keinen andern Trank als die paar Tropfen Wassers, mit denen sie ihr Brot anfeuchten, um es nur zerbeißen zu können. Und was sollten diese harten, im Verzicht an sich den höchsten Lebenszweek erkennenden Gesellen mit den Bewohnern des Sarapeums zu thun haben, die über den Hunger, den sie leiden müssen, beweglich zu klagen verstehen, die aber sicherlich in solcher Enthaltsamkeit nicht die Hauptaufgabe ihres Berufes erblickten!

Und ebensowenig läßt sich ein derartiger Einfluß auf die Entstehung der ältesten Klosteranlagen nachweisen. Nicht alle waren stark genug, auf sich allein gestellt, das Leben in der Einsamkeit zu ertragen. Mancher war schon zu alt, wie jener einfältige Paulus, der zu Antonius ging und ihn durch seine unbeugsame Beharrlichkeit und seinen kindischen Gehorsam bezwang. Für diese Schwächeren ist das Kloster der gegebene Ort. Auch es war gedacht als eine Sammlung von Einzelzellen, in denen jeder für sich leben konnte, aber in ihm war das Leben doch wesentlich leichter zu ertragen als in der Wüste. Daß Pachomius, der die erste Organisation schuf, ursprünglich ein Sarapismönch gewesen sei, oder überhaupt mit dem Sarapisdienst in Verbindung gestanden habe, ist ein Irrtum, den jüngst Ladeuze hoffentlich für immer aus der Welt geschafft hat ${ }^{2}$ ), und so fallt auch hier die letzte Möglichkeit einer Verbindungslinie zwischen der alten und der neuen Zeit hin.

Dennoch aber liegt der Weingarten'schen Vermutung ein gesunder Gedanke zu Grunde, der freilich hier nicht näher ausgeführt werden kann. Die x.́zoxot verewigen durch ihren Namen ein religionsgeschichtliches Element, das auch für die Entstehung des Mönchtums ohne Zweifel von einer weit größeren Bedeutung gewesen ist, als sich das aus den gangbaren Darstellungen erkennen läßt. Von den altisraelitischen Propheten, den Rekabitern, Essenern und Therapeuten führt über die altchristlichen Propheten, Märtyrer und Asketen eine Linie hin zu jenen Einsiedlern, die in der nitrischen Wüste ihr Fleisch kreuzigten. Sie alle waren in irgend einer Weise Besessene, d. h. von der Gottheit Ergriffene und sie alle hatten nur das Ziel, ihres Gottes zu leben. Lassen sich, wie auf den vorstehenden Blättern gezeigt wurde, auch die «Besessenen» des Sarapis hierin eingliedern, so ergiebt sich daraus eine religionsgeschichtliche Konsequenz, die man bei der Erklärung der Lebensformen des alten Christentums nicht außer acht lassen darf. Es muß an dieser Stelle mit diesem allgemeinen Hinweise genügen; an anderer Stelle wird sich Gelegenheit geben, die hier angedeuteten Gedanken weiter auszuführen.

1) Vgl. die sehr verstiandigen Bemerkungen, die Brunet de Presle, Notices, p. 311, hierüber macht. - 2) P. Ladeuze, Étude sur le cénobitisme Pakhomien, Louvain 1898, p. $157 \mathrm{ss}$. 